\title{
A Procedure for Performing Nonlinear Pushover Analysis for Tsunami Loading to ASCE 7
}

(1)

Marco Baiguera $^{1}$, A.M.ASCE, Tiziana Rossetto², A.M. ASCE, Ian N. Robertson ${ }^{3}$, M.ASCE; and

\author{
Crescenzo Petrone ${ }^{4}$
}

\author{
${ }^{1}$ Research Fellow, Dept. of Civil, Environmental and Geomatic Engineering, University College London, \\ Gower Street, London, WC1E 6BT, United Kingdom (corresponding author). Email: m.baiguera@ucl.ac.uk \\ ${ }^{2}$ Professor, Dept. of Civil, Environmental and Geomatic Engineering, University College London, Gower \\ Street, London, WC1E 6BT, United Kingdom \\ ${ }^{3}$ Professor, Dept. of Civil and Environmental Engineering, Univ. of Hawaii at Manoa, Honolulu, HI 96822 \\ ${ }^{4}$ Senior Earthquake Analyst, Willis Towers Watson, Lime Street, London, EC3M 7DQ, United Kingdom
}

\section{ABSTRACT}

The new ASCE 7-16 Chapter 6 offers a comprehensive and practical methodology for the design of structures for tsunami loads and effects. While it provides prescriptive tsunami loading and design requirements, Chapter 6 also allows for the use of performance-based nonlinear analysis tools. However, the specifics of load application protocol, and system and component evaluation for such a nonlinear approach are not provided. This paper presents a procedure for performing nonlinear static pushover analysis for tsunami loading within the framework of the ASCE 7-16 Standard. Through this approach, the user can both estimate the effective systemic lateral-resisting capacity of a building and the local component demand. This enables the identification of deficiencies in structural elements with respect to the ASCE 7-16 standard acceptance criteria. To demonstrate the procedure, a prototypical reinforced concrete multi-story building exposed to high tsunami hazard in the US Northwest Pacific coast is assessed. This is a building with sufficient height to provide last-resort refuge for people having insufficient time to evacuate outside the inundation zone. The results of the nonlinear static pushover analyses show that the structural system has sufficient lateral strength to resist ASCE 7-16 prescribed tsunami loads, but fails the checks for component-based loading, with the exterior ground story columns observed to fail in flexure and shear. The example demonstrates that use of the tsunami nonlinear static 
analysis procedure allows the identification of structural deficiencies such that a targeted strengthening of the building can be conducted, (i.e. flexural and shear strengthening of the seaward and inland columns, for the case study building presented), leading to significantly reduced costs.

Keywords: Tsunami; ASCE 7 Standard; Nonlinear Static Analysis; Push over analysis.

\section{INTRODUCTION}

The catastrophic effects of recent tsunami triggered by large subduction earthquakes in the Indian Ocean (2004) and Japan (2011) have highlighted the tsunami threat posed to many coastal communities in the United States and around the world. Community preparedness in tsunami-prone areas of Alaska, Washington, Oregon, California and Hawaii has improved recently through installation of warning systems and increased preparedness for evacuation. However, there are many communities that have limited access to high ground and have insufficient time for complete horizontal evacuation. Under this scenario, taller buildings could potentially offer a safe haven. Critical facilities and multi-story buildings could be designated as vertical evacuation refuges if they have been designed and constructed to withstand tsunami loads.

To increase the resilience of coastal communities and mitigate tsunami damage to important structures, tsunami design procedures are now included in US design codes through the introduction of a new Chapter 6, Tsunami Loads and Effects, in ASCE 7-16, Minimum Design Loads and Associated Criteria for Buildings and Other Structures (ASCE, 2017a). This design standard has been included by reference in the requirements of the 2018 International Building Code (IBC, 2018), and an extensive guide to the provisions with example applications is now available in Robertson (2020). The ASCE 716 tsunami design provisions apply to essential (risk category IV) and critical (risk category III) facilities, and designated tsunami vertical evacuation structures located within the mapped Tsunami Design Zone (TDZ). Although not required by ASCE 7-16, local communities are strongly encouraged to require tsunami design for taller risk category II buildings (residential, commercial, etc.) in the TDZ to provide additional options of refuge-of-last-resort for those unable to evacuate to high ground or to a designated vertical evacuation structure. This also improves community resilience by ensuring that 
important and substantial buildings survive the tsunami and can be re-occupied relatively soon after the event.

The Tsunami Design Zone (TDZ) is the area vulnerable to being inundated by the Maximum Considered Tsunami (MCT), defined as having $2 \%$ probability of being exceeded in a 50 -year period, equivalent to a 2500-year return period. Figure 1 outlines the main steps for the evaluation of buildings in the TDZ. In essence, ASCE 7-16 defines hydrostatic, hydrodynamic and debris impact loads, load combinations, importance factors and acceptance criteria for two main types of structural checks:

1. A systemic check - wherein the structural lateral-force-resisting systems (LFRS) are checked for their adequacy in resisting the prescribed tsunami loading.

2. A component-based check - wherein the design strength of each individual structural component is checked for adequacy against an enhanced tsunami loading that accounts for local drag effects.
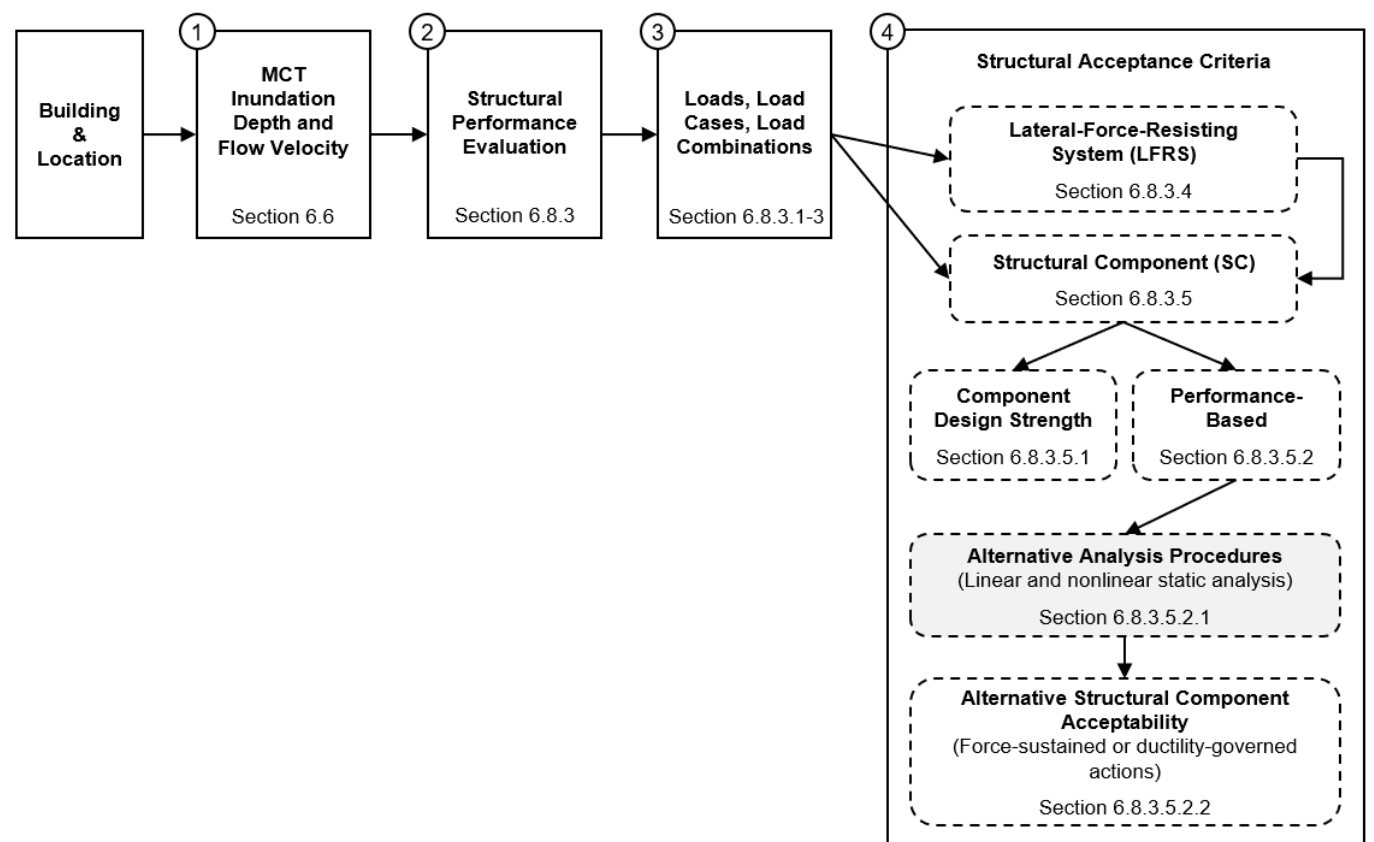

Figure 1: Tsunami nonlinear static analysis within the framework of ASCE 7-16 tsunami design provisions (Section numbers refer to ASCE 7-16 (2017a)).

Within the ASCE 7-16 standard, a simplified approach is proposed for use in the systemic check. In this simplified check, the acceptance criterion for LFRS is based on a comparison between the tsunami lateral load applied and the structure's seismic design base shear, enhanced to include typical overstrength. For the component-based check, the prescriptive approach is to ensure that the component 
design strength is larger than the internal forces obtained using a linear elastic, static analysis of the component subjected to the prescribed tsunami loading cases. For structural components that are part of the LFRS, the component internal forces must be combined with internal forces induced by the tsunami loads on the overall building system.

As an alternative to the simplified systemic check and prescriptive component-based check, the ASCE 7-16 standard allows for the use of performance-based criteria to assess structural response. This includes the adaptation of nonlinear static pushover analysis of ASCE 41-17 (ASCE, 2017b) to tsunami loading. However, no detailed guidance is provided as to how these performance-based methods should be carried out.

Performance-based engineering methods for tsunami are much less developed than for other hazards, such as earthquakes. For instance, in seismic engineering, nonlinear static and dynamic analysis, generally referred to as pushover analysis and time-history analysis, respectively, are wellestablished tools for performance-based design and assessment of structures. In reality, pushover analysis is a crude approximation of the highly dynamic loading and induced damage that occurs during a seismic event. However, when applied in the context of tsunami loading, pushover analysis can, in fact, very closely replicate the actual hydrodynamic drag on the overall structure and individual structural components, as these forces are typically of long duration (Foster et al., 2017).

The complexity of understanding the impact of onshore tsunami inundation on coastal structures, and the challenges in developing inundation models that can simulate realistic tsunami loads and resulting effects, have hampered the development of analytical methods (Rossetto et al., 2018). Recent advances in physical modelling of tsunami and new field observations from tsunami reconnaissance missions have led to the definition of new analysis approaches that apply realistic tsunami loads to the structure and account for the material nonlinearity of structural elements.

Structural analysis methodologies for tsunami have often been adapted from commonly-used nonlinear static analysis methods for earthquake loading. Macabuag et al. (2014) performed a sensitivity study to compare the structural response of a simple reinforced concrete (RC) frame under different code-based tsunami loadings, including those prescribed by ASCE 7-16. Hydrodynamic forces were applied to each inundated story of the building along the seaward columns, assuming a constant tsunami 
inundation depth and increasing flow velocity. This approach is herein referred to as constant depth pushover (CDPO). CDPO is similar to a seismic pushover analysis, since the lateral tsunami force distribution remains constant while the magnitudes of the individual forces are increased monotonically. Hence, this approach can be implemented easily in structural analysis software that performs seismic pushover analysis. Attary et al. (2017) performed CDPO analyses in a fragility assessment of a low-rise steel moment-resisting frame structure. Random sets of tsunami depth and flow velocity values were used to generate a suite of tsunami forces using the expressions in FEMA P-646 (FEMA, 2012), and were then applied at each story level. Alam et al. (2018) used a similar approach for the fragility assessment of an existing six-story RC school. In the latter, the CDPO analysis approach was implemented applying distributed loading along the vertical structural members and explicitly accounting for the shear failure of columns. The hydrodynamic tsunami force was estimated based on the ASCE 7-16 Standard provisions. Since no specific building location was selected, CDPO analyses were performed using a random suite of inundation depths and velocities.

In the context of fragility assessment, Petrone et al. (2017) developed novel approaches for the analysis of structural performance under tsunami loading: namely tsunami time-history dynamic analysis (TDY) and variable depth pushover (VDPO). The TDY procedure follows the same principles as a seismic time-history analysis, apart from the input data, which is the tsunami force estimated from a simulated inundation time-history. In the VDPO analysis, the lateral tsunami force applied to the structure is incrementally increased by monotonically increasing the tsunami inundation depth at the site of the structure. At each depth value, the corresponding flow velocity is calculated assuming a constant Froude number $(\mathrm{Fr})$. A curve of tsunami base shear versus total drift can be plotted from the analysis, and the structural performance is assessed from this tsunami pushover curve at the location where the tsunami base shear equals the applied tsunami loading. TDY and VDPO are shown to provide consistent results in Petrone et al. (2017), Rossetto et al. (2019) and Petrone et al. (2020), with the VDPO analysis outperforming the CDPO analysis in terms of engineering demand parameter estimation, (i.e. inter-story drifts and column shear forces). All these studies have shown that the tsunami fragility of RC buildings is significantly influenced by the occurrence of shear failure in the columns. To capture this effect, the tsunami hydrodynamic loads are discretized into point loads 
distributed along each column. In addition, the tsunami hydrodynamic force was estimated from experimentally-validated equations by Qi et al. (2014), which account for the regime conditions of the

127 flow impacting the structure and the density of the urban environment.

The main limitation of the VDPO as originally conceived is that being a load-control analysis, VDPO is not capable of capturing the degrading portion of the pushover curve. This limitation was overcome by Baiguera et al. (2019) through the development of the VDPO2 approach, which consists of a two-phase nonlinear static analysis. In Phase 1 of the VDPO2, a load-control pushover analysis is conducted assuming that the inundation depth and flow velocity increase incrementally. This phase is essentially a replication of the VDPO. In Phase 2, the analysis switches to response-control pushover analysis, where the displacement is increased incrementally and the corresponding tsunami force is calculated. For the latter force calculation, the same inundation depth and load distribution as in the last step of Phase 1 of the analysis is assumed, with force increase attributed to an increase in the flow velocity (as in the CDPO). The switch from Phase 1 to 2 occurs either when a predefined load level is reached or when the analysis encounters a numerical convergence issue, whichever occurs first. In the latter case, the Phase 1 analysis is repeated up to the time step preceding the numerical convergence issue, and then Phase 2 is initiated.

The objective of this paper is to present a methodology whereby the VDPO2 can be applied for tsunami design of buildings located in the TDZ, following the ASCE 7-16 provisions. For ease of reference, this new approach will be termed ASCE-VDPO2. To demonstrate the ASCE-VDPO2 approach, a prototypical RC frame selected from the design examples in Robertson (2020) is used as a case study. The advantages of using a pushover analysis approach for design compared to the prescriptive acceptance criteria of the ASCE 7-16 provisions are discussed.

\section{TSUNAMI LOADING}

The ASCE 7-16 Chapter 6, Tsunami Loads and Effects, provides a practical methodology to calculate the overall and component tsunami loads on a structure. These are presented in this section as they are adopted in the proposed ASCE-VDPO2 analysis method for consistency with the standard. 


\section{Tsunami Load Calculation for the LFRS Systemic Check}

The tsunami load on a structure, $F_{\mathrm{T}}$, which is used for conducting the systemic check on the LFRS,

153 is estimated using the following hydrodynamic drag equation:

$$
F_{\mathrm{T}}=\frac{1}{2} \rho_{\mathrm{s}} I_{\mathrm{tsu}} C_{\mathrm{d}} C_{\mathrm{cx}} B\left(h u^{2}\right)
$$

154

where $\rho_{\mathrm{S}}$ is the minimum fluid mass density, $I_{\mathrm{tsu}}$ is the tsunami importance factor for hydrodynamic loads $\left(I_{\text {tsu }}=1\right.$ for TRC II buildings, $), C_{\mathrm{d}}$ is the drag coefficient, $B$ is the building width perpendicular to the flow, $h$ is the inundation depth, $u$ is the flow velocity, and $C_{\mathrm{cx}}$ is the proportion of closure coefficient (with a minimum value of 0.7 , adopted in this study). The drag coefficient $C_{\mathrm{d}}$ varies based on the $B / h$ ratio. Figure 2 plots the tabular $C_{\mathrm{d}}-B / h$ data for rectilinear buildings given in Table $6.10-1$ (ASCE 2017a), along with the linear interpolations between intermediate values that have been derived in this paper. The corresponding equations are provided in the Appendix.

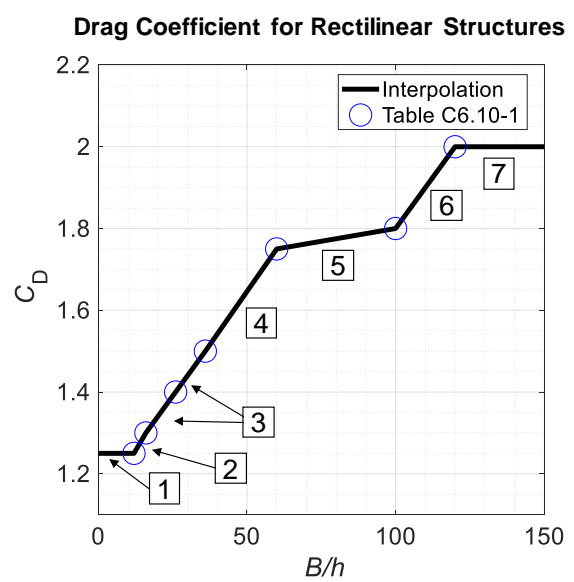

Figure 2: Linear interpolations of drag coefficient-width to inundation depth ratio $B / h$ values from Table C6.10-1 (ASCE, 2017a). Numbers in boxes indicate the curve branches whose equations are provided in Table 1 in the Appendix.

For wide buildings, the overall drag is large for small inundation depths due to the large pressure differential between the front and the back, since it takes longer for the water to equalize on opposite sides of the building. The minimum fluid mass density $\rho_{\mathrm{S}}$ is $1127.5 \mathrm{~kg} / \mathrm{m} 3$, estimated as follows:

$$
\rho_{\mathrm{s}}=k_{\mathrm{S}} \rho_{\mathrm{sw}}
$$

where $\rho_{\mathrm{sw}}$ is the seawater mass density taken as $1,025 \mathrm{~kg} / \mathrm{m}^{3}$ and $k_{\mathrm{S}}$ is the fluid density factor that accounts for a $10 \%$ increase in density due to suspended solids and other small objects, i.e. $k_{\mathrm{S}}=1.1$. 
curves are normalized to the maximum values of inundation depth, $h_{\max }$, and velocity, $u_{\max }$, at the building site to make them generally applicable. The values of $h_{\max }$ and $u_{\max }$ at a building site can be determined by applying the Energy Grade Line Analysis (Kriebel et al., 2017). No equations are provided by ASCE 7-16 that describe the shape of the normalized time-history curves. Hence, in this paper, to aid with the ASCE-VDPO2 analysis, a least squares error analysis was performed to develop the best fit expressions shown in Table 2 in the Appendix. The maximum lateral hydrodynamic force on the structure, $F_{\mathrm{T}, \mathrm{LC} 2}$, occurs when the velocity reaches its peak in each direction and the inundation depth is $2 / 3$ of $h_{\text {max }}$. This stage, indicated as Load Case 2 (LC2), controls the design of the LFRS.

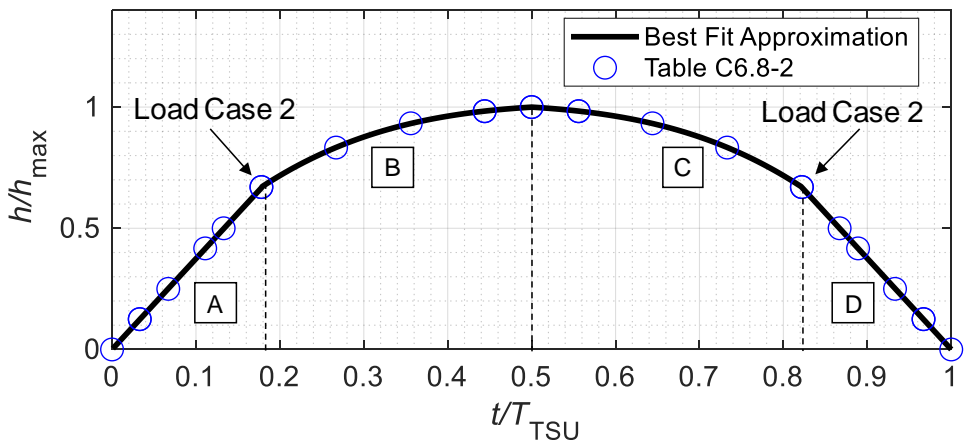

(a)

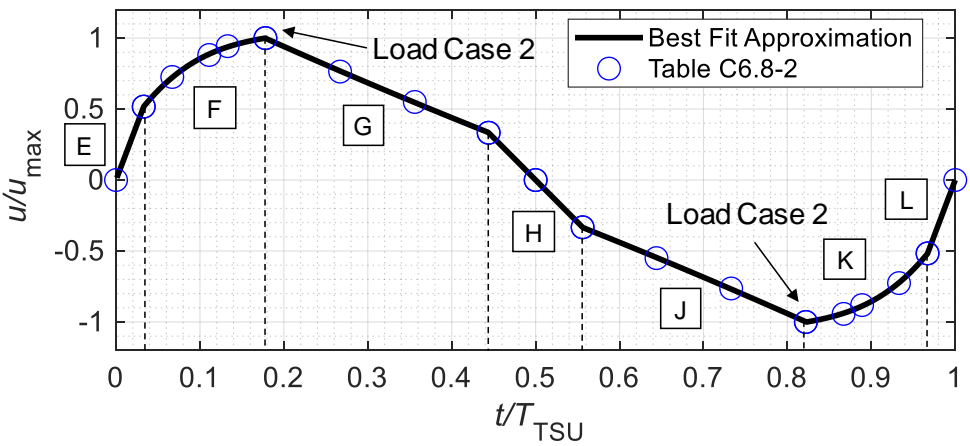

(b)

Figure 3: Best-fit approximations of the normalized time inundation depth (a) and flow velocity (b) curves from Figure 6.8-1 and Table C6.8.2 (ASCE, 2017a). Letters in square boxes indicate the branches of the curves. The corresponding best-fit equations are provided in Table 2 in the Appendix.

Figure 4 shows typical tsunami time-history curves together with the resulting lateral hydrodynamic force on the overall building from Eqn. (1). The curves are derived for the case-study building presented later in this paper, which is sited in Seaside, Oregon, and is $77.4 \mathrm{~m}$ wide in the direction perpendicular to the tsunami flow. At the building site, $h_{\max }$ and $u_{\max }$, are $9.57 \mathrm{~m}$ and $11.56 \mathrm{~m} / \mathrm{s}$, respectively. 

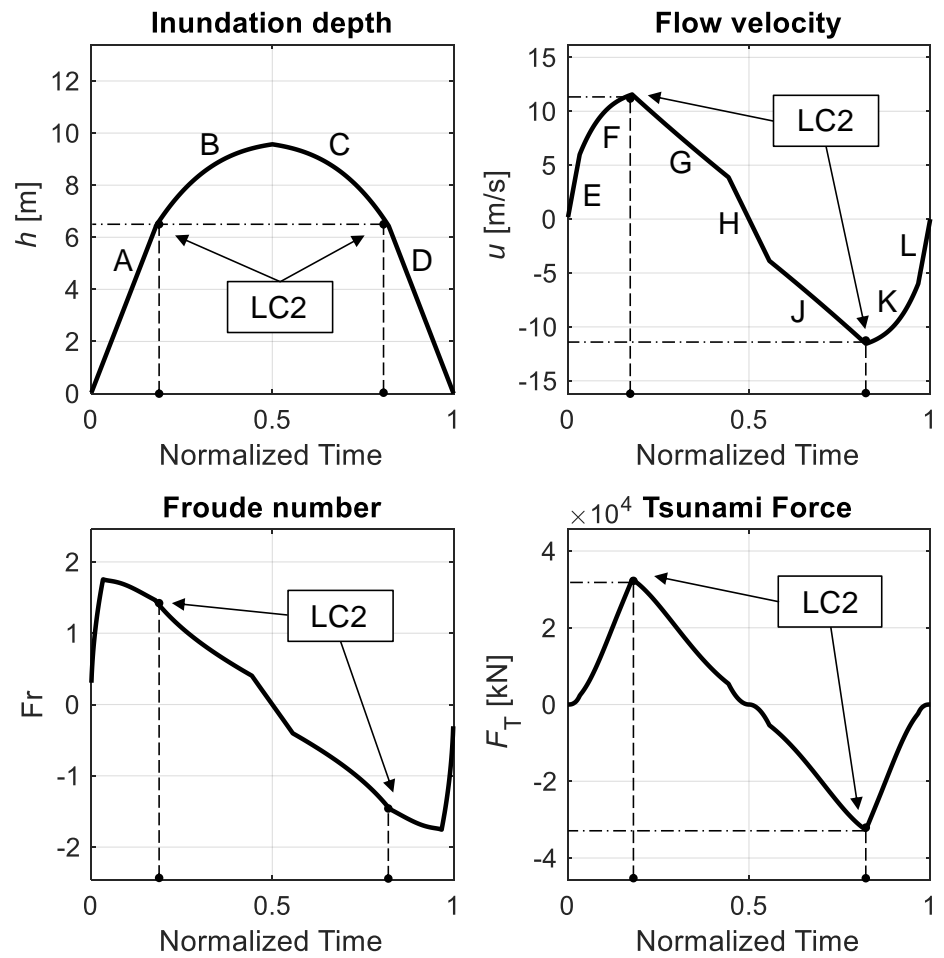

Figure 4: Example of tsunami inundation time-history curves for the case-study building in Seaside, Oregon.

ASCE 7-16 requires that tsunami loads be combined with other loads according to the load combinations provided in ASCE 7-16 Section 6.8.3.3 as:

$$
\begin{gathered}
0.9 D+F_{\mathrm{TSU}}+H_{\mathrm{TSU}} \\
1.2 D+F_{\mathrm{TSU}}+0.5 L+0.2 S+H_{\mathrm{TSU}}
\end{gathered}
$$

182 where $D$ is the dead load, $L$ is the live load, $S$ is the snow load, $F_{\text {tsu }}$ is the tsunami load for incoming

183 and receding directions of flow, and $H_{\text {TSU }}$ is the load caused by tsunami-induced lateral foundation

184 pressures developed under submerged conditions. The load combinations given in Eqns. (3) and (4) are consistent with the Extraordinary Load Combinations specified in ASCE 7-16 Section 2.5.

Tsunami Load Calculation for the Component-based Check

All structural components that are part of the LFRS are subjected to the net resultant of their participation in resisting the overall drag force (Eqn. 1) and the hydrodynamic drag caused by local

189 flow around the individual component. The latter is given by Eqn. (5) and is applied as a distributed load on the projected inundated height $h_{\mathrm{e}}$ :

$$
F_{\mathrm{d}}=\frac{1}{2} \rho_{\mathrm{S}} I_{\mathrm{tsu}} C_{\mathrm{d}} b\left(h_{\mathrm{e}} u^{2}\right)
$$


where $b$ is the effective width of the component and $C_{\mathrm{d}}$ depends on the shape of the individual member being considered. For all exterior components that are likely to be subjected to debris accumulation, $C_{\mathrm{d}}$ $=2$ and $b$ is taken as the tributary width multiplied by $C_{\mathrm{cx}}$ (ASCE, 2017a).

\section{THE ASCE-VDPO2 NONLINEAR PUSHOVER ANALYSIS FOR TSUNAMI LOADING}

The VDPO2 structural analysis method presented in Baiguera et al. (2019a, 2019b) is here modified to be consistent with the requirements of ASCE 7-16 and ASCE 41-17. The ASCE-VDPO2 adopts a two-phase analysis approach, with a load-control first phase followed by a response-controlled second phase, as described previously.

\section{Analysis Procedure for Design - ASCE-VDPO2 Phase 1}

For the systemic check in ASCE 7-16 the strength of the LRFS is checked against the 2,500-year Maximum Considered Tsunami (MCT). In ASCE-VDPO2, therefore, the Phase 1 loading is based on the ASCE 7-16 inundation time histories, presented previously, up to LC2. The tsunami inundation depth is increased monotonically following sector A in Figure 3a, with the corresponding flow velocity given in sectors $\mathrm{E}$ and $\mathrm{F}$ in Figure $3 \mathrm{~b}$ at the same time step. Figure 5a illustrates the plots of inundation depth, flow velocity, Froude number and tsunami force time-histories up to LC2 for the case-study building presented later in the paper.
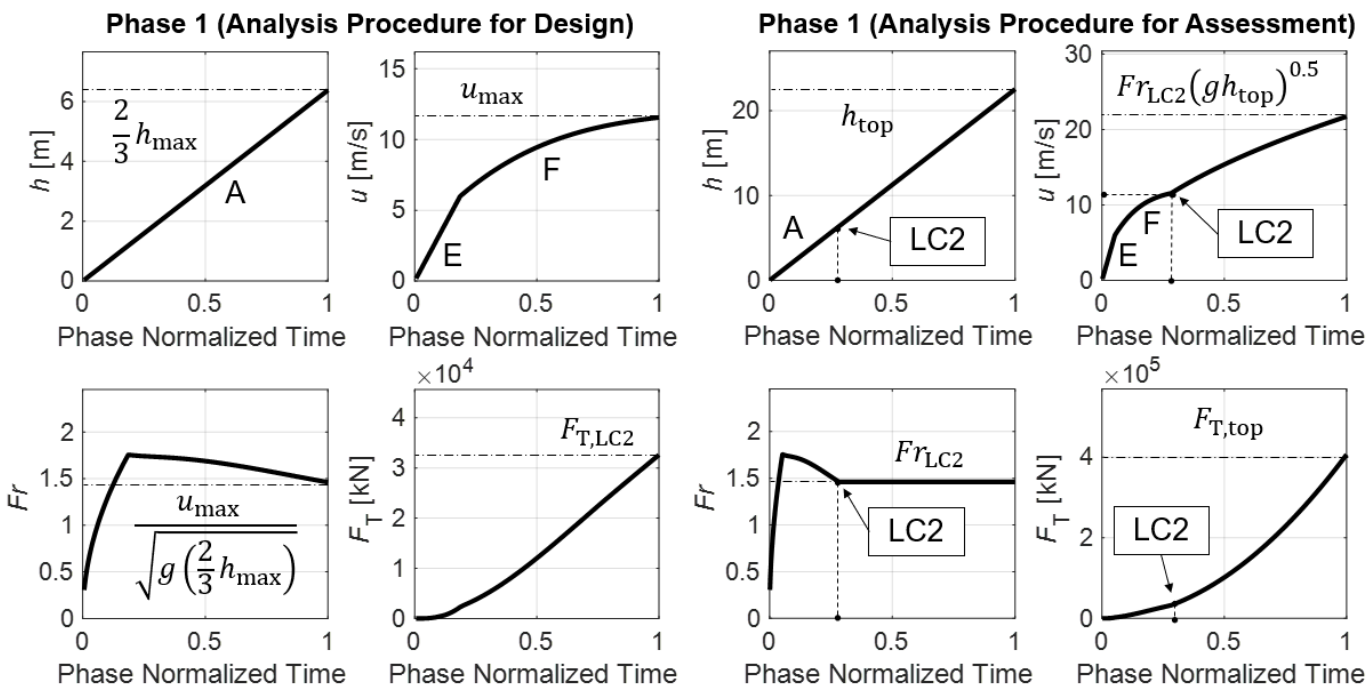

(a)

(b)

Figure 5: Example of Phase 1 for the case-study building: (a) design; (b) assessment. 


\section{Analysis Procedure for Design - ASCE-VDPO2 Phase 2}

In Phase 2, the analysis switches to response-control pushover analysis, where the displacement is increased incrementally and the corresponding tsunami force is calculated. The switch from Phase 1 to 2 occurs either when LC2 is reached or when the analysis encounters a numerical convergence issue, whichever occurs first. In the former case, the switch to response-control occurs immediately, with the same inundation depth and load distribution as in LC2 being assumed. In this case, the force increases as the flow velocity increases for the constant inundation depth, $2 / 3 h_{\max }$. In the case where numerical instability precedes LC2, the Phase 1 analysis is repeated up to the time step preceding the numerical convergence issue, and then Phase 2 is initiated. The occurrence of a numerical instability before achievement of LC2 does not necessarily mean that the structure has failed before reaching LC2, and the response-control analysis allows the identification of the structural peak capacity, which may or may not exceed the load associated with LC2. For instance, numerical convergence issues might occur during the load-control (Phase 1) due to the inability to capture the degrading branch of the pushover curve.

\section{Analysis Procedure for Assessment - ASCE-VDPO2 Phases 1 and 2}

The proposed analysis procedure can also be employed to assess the LFRS for inundation depths and flow velocities larger than the ones for the design basis event (i.e. LC2). Such assessment is performed by first conducting the same Phase 1 analysis as for design up to LC2, and once LC2 is reached, the inundation depth continues to be increased linearly up to the top of the building, with the flow velocity calculated assuming a constant Froude number, taken as the Froude number at LC2, as illustrated in Figure 5b. Similar to before, the switch from Phase 1 to 2 occurs either when the inundation depth equals the building height, or when the analysis encounters a numerical convergence issue, whichever occurs first. In the former case, the switch to response-control occurs immediately, with a constant inundation depth (the building height) used and the same load distribution as in the last step of the Phase 1 analysis. In the case where numerical instability occurs, the Phase 1 analysis is repeated up to the time step preceding the numerical convergence issue, and then Phase 2 is initiated. In this case, Phase 2 assumes a constant inundation depth and the same load distribution as in the last step of the Phase 1 analysis. 
The simplified systemic check in ASCE 7-16 compares the overall tsunami force to the design 237 seismic base shear, and does not require a structural analysis per se. However, the component-based 238 check does require an elastic analysis. For conducting the ASCE-VDPO2 analysis a load discretization 239 approach is needed for both systemic and component-based checks. The flowchart in Figure 6 240 summarizes the main steps of the analysis procedure for design.

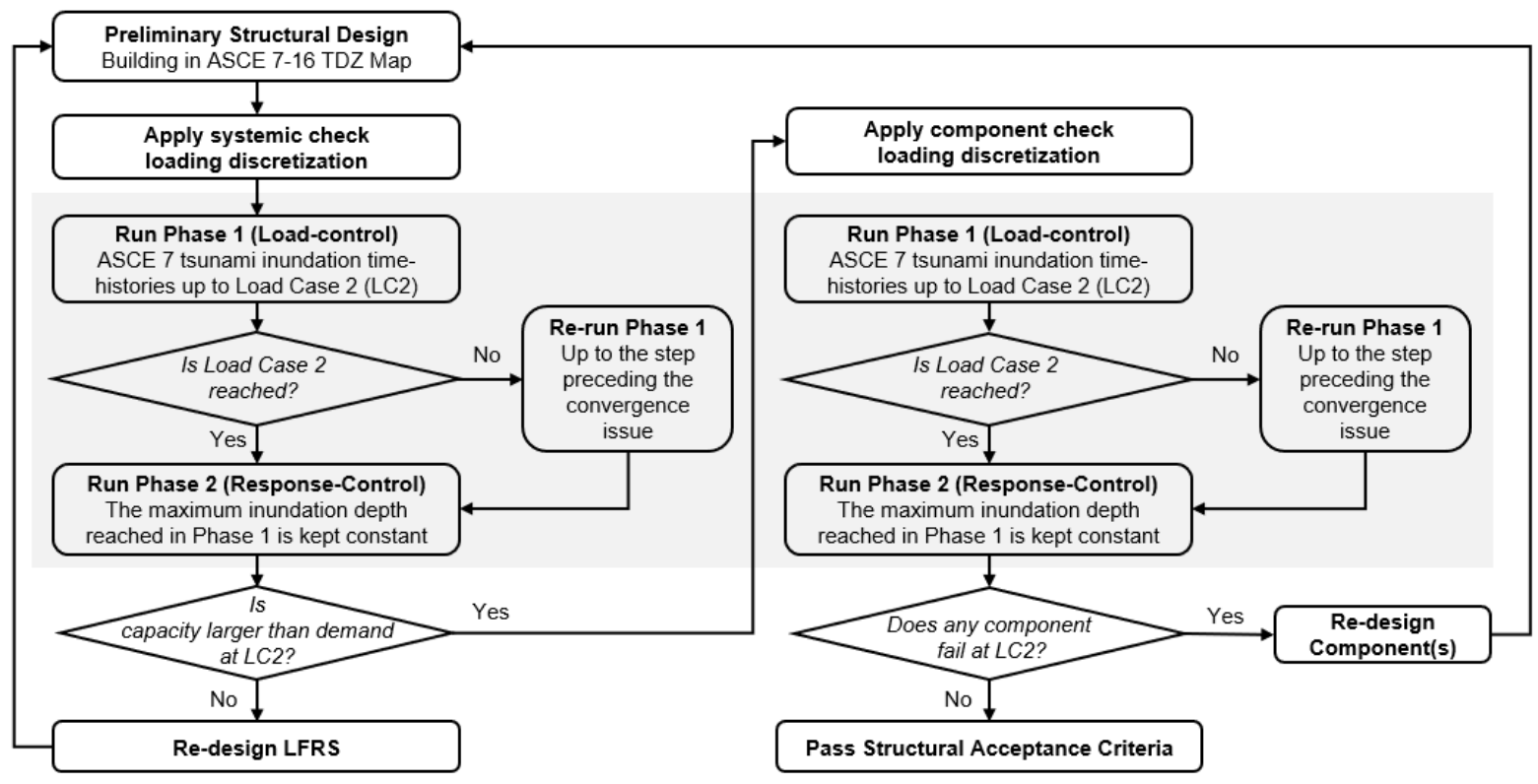

Figure 6: Flowchart of ASCE-VDPO2 for design.

\section{Systemic Check Load Discretization}

ASCE 7-16 specifies that the systemic tsunami lateral load on the building be considered as uniformly distributed on the coastal and inland elevations of the building. The overall tsunami force $F_{\mathrm{T}}$ can be discretized into $j$ forces $\left(f_{c, j}\right)$, each applied to a line of external columns based on their tributary width. Figure 7 illustrates the discretization of $F_{\mathrm{T}}$ for the case-study building presented later. 


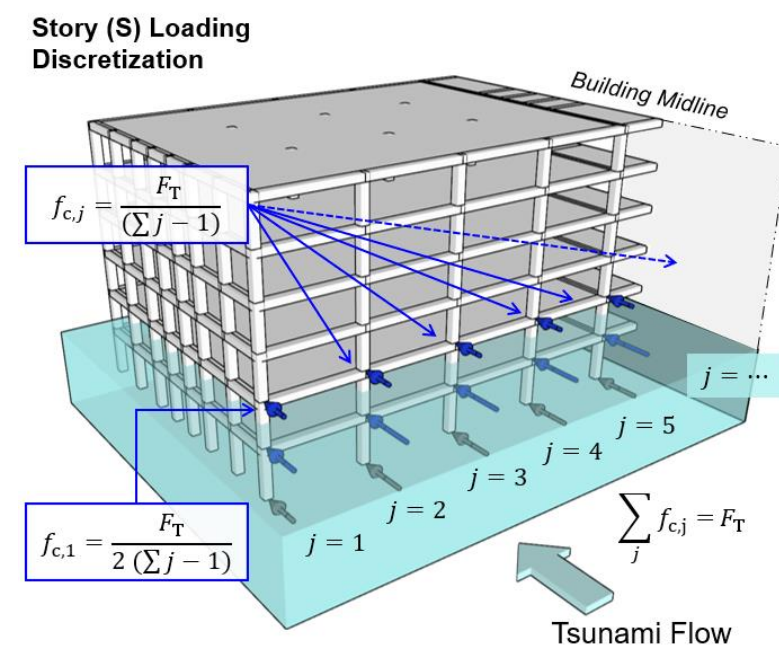

(a)

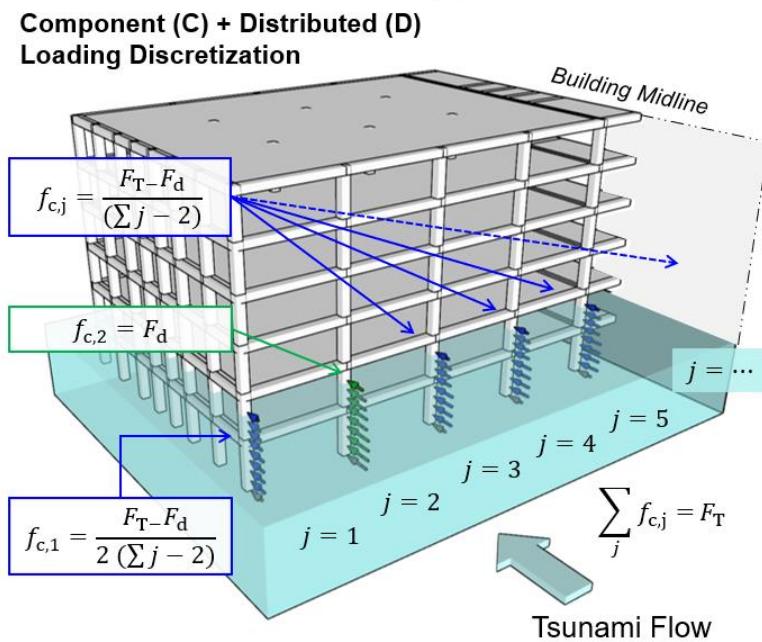

(c)

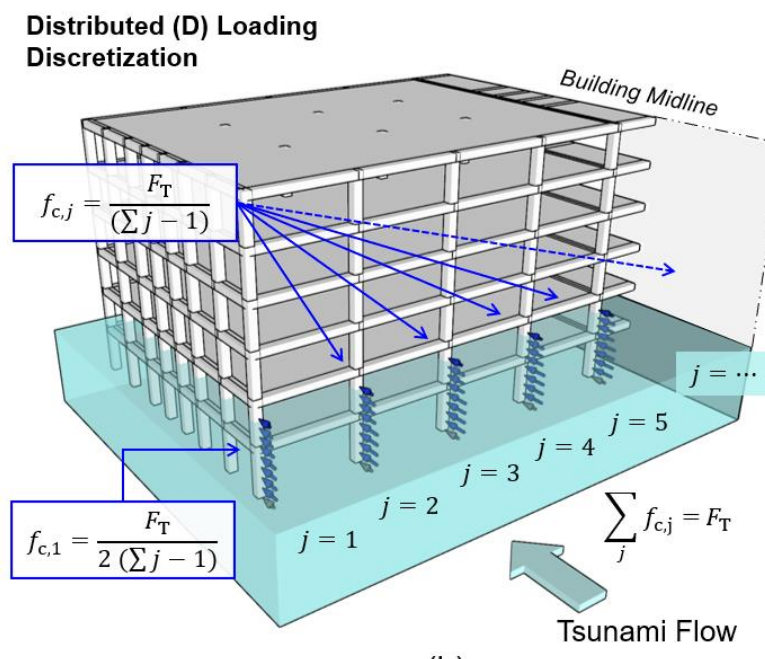

(b)

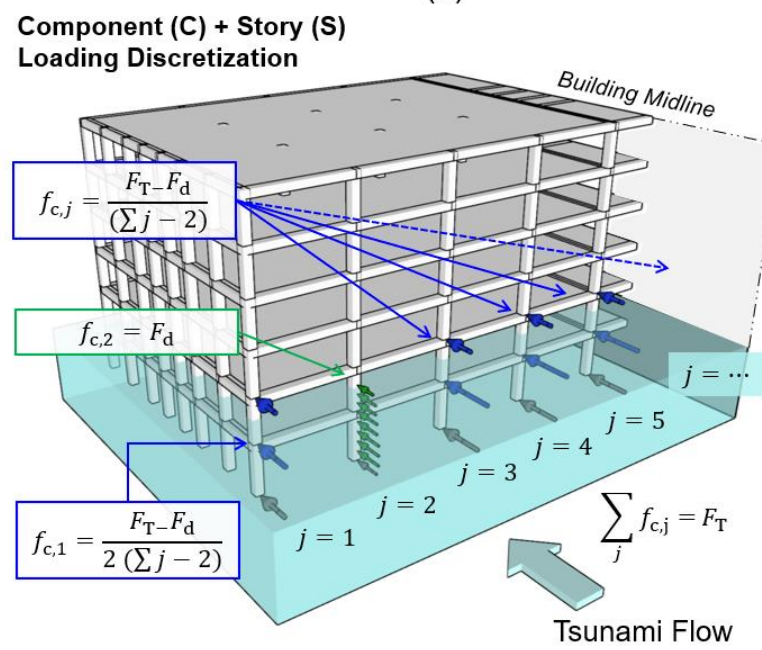

(d)

Figure 7: Example of loading discretization methods applied to one half of the case-study building at Load Case 2: (a) $S$ discretization for overall hydrodynamic loads (shown in blue color); (b) D discretization for overall hydrodynamic loads (shown in blue color); (c) $C+D$ discretization for component hydrodynamic loads (with component loads in green color) ;

(d) $C+S$ discretization for component hydrodynamic loads (with component loads in green color). The loads that are transferred directly to the foundations are shown in grey color to indicate that they are not accounted for in the analyses.

However, ASCE 7-16 does not prescribe how the force should be discretized and applied along the columns. An approach used in past studies is to apply nodal loads to each story, referred to hereafter as

250 the story $(S)$ loading discretization. The tsunami forces are calculated using a simple influence area approach. As shown in the example in Figure 8a, portion of the load is transferred directly to the foundations $\left(f_{1}\right)$ while portion is applied to the second and third floors $\left(f_{2}\right.$ and $\left.f_{3}\right)$. Hence, $f_{\mathrm{c}, \mathrm{j}, \mathrm{net}}=$ $f_{\mathrm{c}, \mathrm{j}}-f_{1}$ is the net load resisted by the $j$-th line of exterior columns. If this loading discretization is applied to all exterior columns, as illustrated in Figure 7a, the LFRS will effectively resist only a portion of the overall applied building tsunami load, i.e. $F_{\mathrm{T}, \text { net }}=\sum_{j} f_{\mathrm{c}, \mathrm{j} \text {,net }}<F_{\mathrm{T}}$. Hence for $S$ loading 

tall first floor.

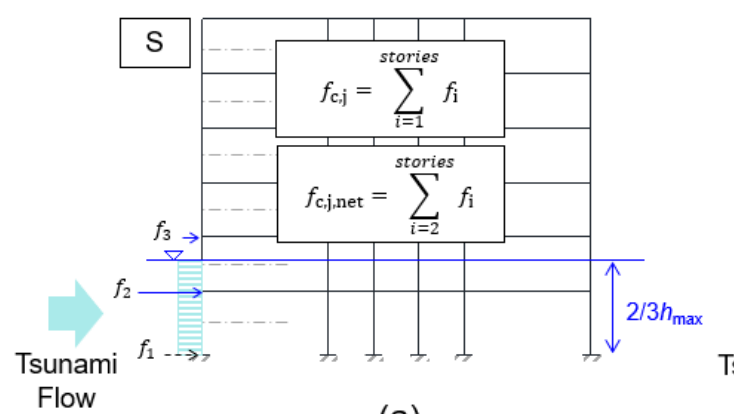

(a)

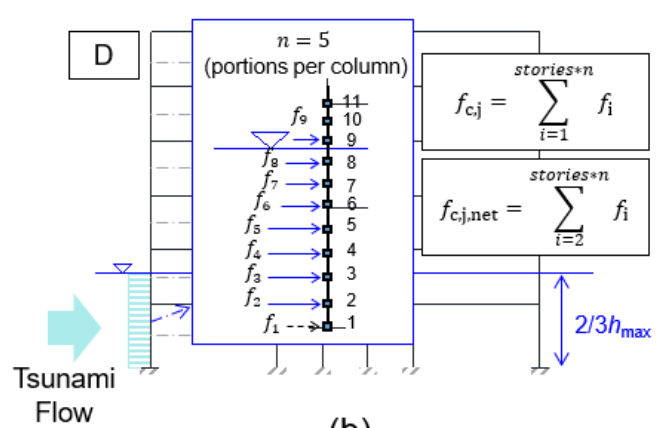

(b)

Figure 8: Loading discretization methods: (a) nodal forces applied to stories (S discretization); and (b) evenly spaced forces applied to columns ( $D$ discretization). The loads that are transferred directly to the foundations are dashed to indicate that they are not accounted for in the analyses.

An alternative approach is to discretize the same hydrodynamic forces into point loads distributed along each column. This method, referred to hereafter as the distributed (D) loading discretization, has been recommended in recent studies (Petrone et al. 2017; Alam et al. 2018), which have shown it to provide the best estimation of demand parameters. If a distributed loading discretization is adopted when using ASCE-VDPO2, it is recommended that for each column, the tsunami loads are applied at 5 load application points along the column height, as illustrated in Figures $7 \mathrm{~b}$ and $8 \mathrm{~b}$. In this case, only the load acting on the lower half of the bottom 1/5th of each column is assigned to the column base. The portion of the load transferred directly to the foundations is much smaller than the one calculated in the $S$ loading discretization. Hence, $F_{\mathrm{T}, \text { net }}$ in the $D$ loading discretization is comparable in magnitude with $F_{\mathrm{T}}$.

Due to the differences in $F_{\mathrm{T}, \text { net }}$ arising from the load discretization, it is clear that the $D$ loading discretization will result in higher shear loads being applied to the LFRS than the $S$ loading discretization. The $S$ loading discretization will instead impart larger moments in the ground story columns due to the loads being applied at a higher level in the structure. In this paper the structural systemic response will be compared for both load discretization assumptions.

\section{Component-Based Check Load Discretization}

The ASCE 7-16 design methodology (Figure 1) requires that every structural element be evaluated for component loads. If the structural component is also part of the LFRS, then the internal forces 
resulting from the component loads must be combined with those resulting from the lateral load on the

277 overall building. Hence, a bespoke loading distribution is proposed in this study, referred to hereafter as the component $(C)$ loading discretization.

279 In order to evaluate the combined effect of systemic and component loads on an exterior column

280 that is part of the LFRS, the component drag force given by Eqn. (5) (i.e., $F_{\mathrm{d}}$ with $C_{\mathrm{D}}=2$ ) is applied to 281 that column as distributed nodal loads. Simultaneously, the remainder of the building lateral load given 282 by Eqn. (1) (i.e., $F_{\mathrm{T}}-F_{\mathrm{d}}$ ) is applied to the remaining columns on the front of the building as distributed 283 loads (Figure 7c) or as nodal loads at each story (Figure 7d). These two options are referred to hereafter 284 as the $C+D$ and $C+S$ loading discretization, respectively.

\section{CASE-STUDY BUILDING}

286 To demonstrate the ASCE-VDPO2 approach, a case study example is used. This section describes 287 the case study building and the finite element modelling approach used.

\section{Prototype building}

A six-story office building is considered as a case-study (Figure 9). The building is located in 290 Seaside, Oregon, which is adjacent to the Cascadia subduction zone and thus characterized by high 291 seismic and tsunami hazards. The Pacific Northwest is at high risk of a potentially destructive tsunami 292 following a Mw 9 earthquake generated along the Cascadia subduction zone (Atwater et al., 1991). 293 Figure 10 illustrates the building location within the ASCE 7-16 2,500-year probabilistic tsunami design zone map of Seaside. Based on the EGLA conducted in McKamey \& Robertson (2019), $h_{\max }$ and $u_{\max }$ at the building site are $9.57 \mathrm{~m}$ and $11.56 \mathrm{~m} / \mathrm{s}$, respectively. 

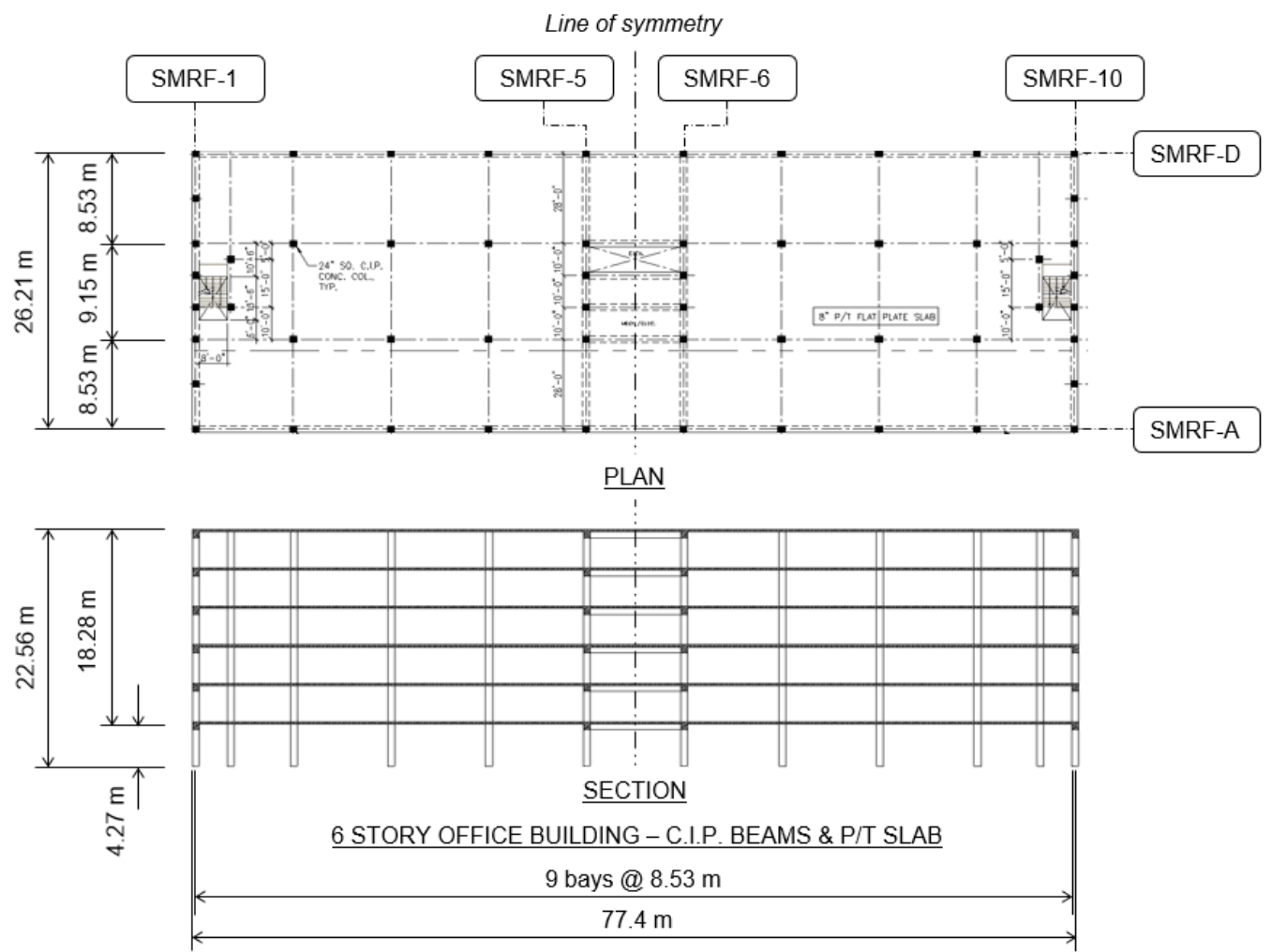

Figure 9: Prototype building (McKamey \& Robertson, 2019).

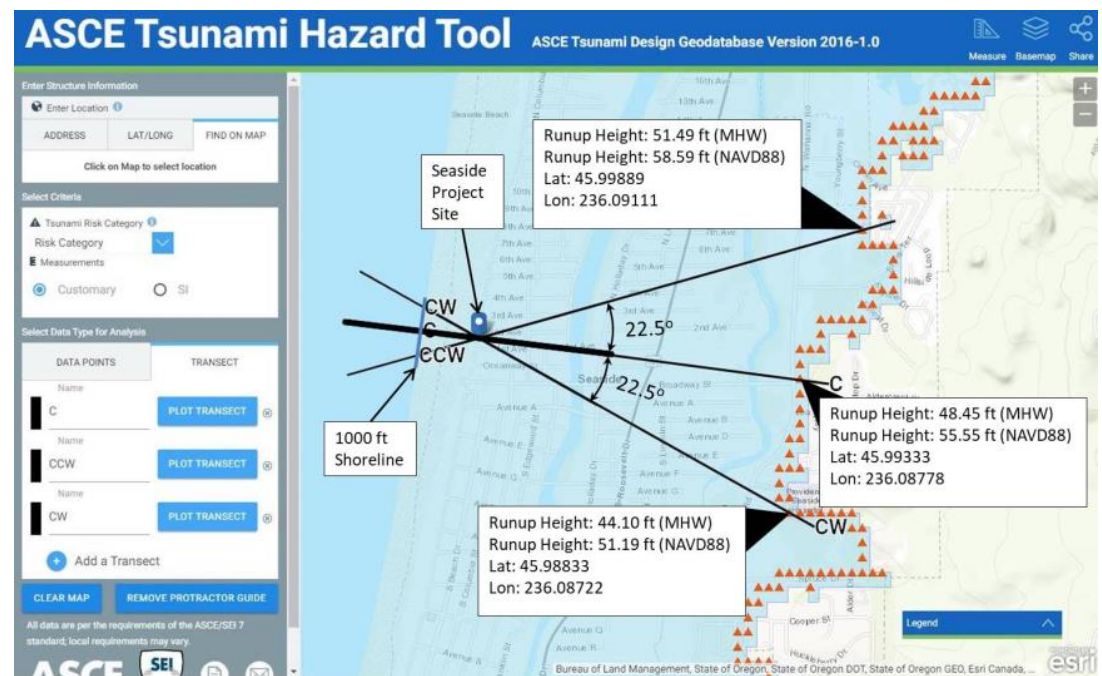

Figure 10: Image from the ASCE Tsunami Hazard Tool showing the prototype building location in Seaside, Oregon, along with the three transects used to perform the Energy Grade Line Analysis (from McKamey \& Robertson, 2019).

The structure is classified as Tsunami Risk Category (TRC) II, and therefore it is not subject to

297 tsunami provisions. However, local jurisdictions are strongly encouraged to require tsunami design for taller TRC II buildings in order to provide secondary refuge-of-last-resort and improve community resilience. Chock et al. (2018) established suitable height thresholds for communities throughout the

300 US Pacific coast, satisfying both the prescriptive acceptance criteria and a recommended height at least 
$3013.66 \mathrm{~m}$ greater than the inundation depth. For the case-study building, the upper three stories would be

302 above $h_{\max }$, hence they could function as a refuge according to the proposal of Chock et al. (2018).

303 The case study building consists of RC special moment resisting frames (SMRF), a flat plate post-

304 tensioned concrete floor system, and interior gravity load columns, as shown in Figure 9. The ground

305 floor consists of a slab-on-grade that is isolated from the building columns. The building was designed

306 for the ASCE 7-16 wind and seismic loads specified for Monterey, California (Robertson, 2020). The

307 building design is appropriate for Seaside, which has similar seismic hazard to Monterey (Seismic

308 Design Category D). Soil classification D for stiff soil is assumed for the building site. The seismic

309 design was carried out assuming the seismic loading combination $1 \mathrm{D}+0.25 \mathrm{~L}$. The corresponding

310 seismic weight is $111,568 \mathrm{kN}$. The lateral force resisting system consists of four SMRFs in the narrow

311 direction (also the assumed tsunami flow direction), denoted as SMRF-1, 5, 6 and 10, and two moment

312 resisting frames in the wide direction (Figure 9), denoted as SMRF-A and D. According to the design

313 specifications, columns and beams have a nominal compressive strength $f_{\mathrm{c}}^{\prime}$ of $27.6 \mathrm{MPa}$ and the

314 reinforcing steel has a nominal yield strength $f_{\mathrm{y}}$ of $414 \mathrm{MPa}$. As illustrated in Figure 11, the size of the

315 columns is uniform along the height of the building, i.e. $71.1 \times 71.1 \mathrm{~cm}$ for the SMRFs, and $61 \times 61 \mathrm{~cm}$

316 for the internal gravity load columns, while the size of SMRF beams is 76.2 wide by $61 \mathrm{~cm}$ deep. The

317 concrete cover is $5 \mathrm{~cm}$. In the SMRF columns, steel reinforcing ratio varies from $1.3 \%$ at the ground

318 floor to $1 \%$ at the upper stories. Transverse reinforcement in the SMRF columns consists of seismic

319 hoops with three $12.7-\mathrm{mm}$-diameter legs at every $10 \mathrm{~cm}$ in the column ends $(71 \mathrm{~cm} \mathrm{long})$ and three 9.5 -

$320 \mathrm{~mm}$-diameter legs every $15 \mathrm{~cm}$ in the central section. More details about the seismic design of the

321 building can be found in Yokoyama and Robertson (2014). Complete tsunami design examples for this

322 building, and a similar shear wall building, located in Seaside, OR, Monterey, CA, Hilo, HI and

323 Waikiki, HI are provided in McKamey and Robertson (2019). 
Ground Floor Columns (SMRFs)

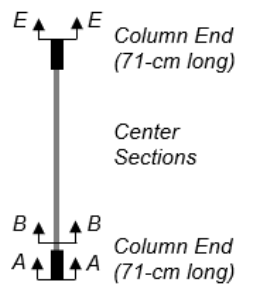

Upper Floors Columns (SMRFs)

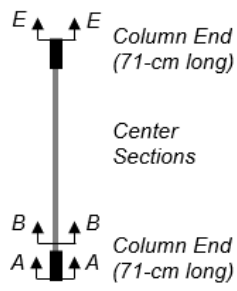

Gravity Columns
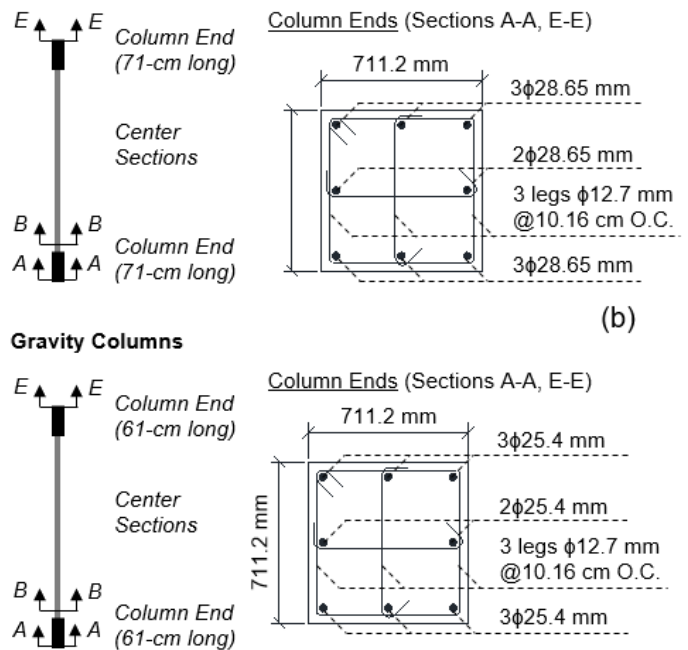

(b)

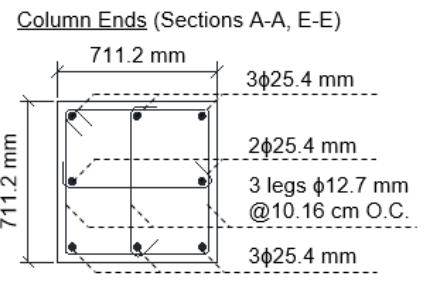

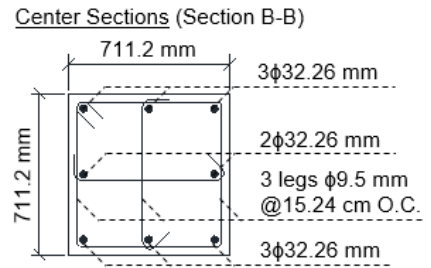

Center Sections (Section B-B)

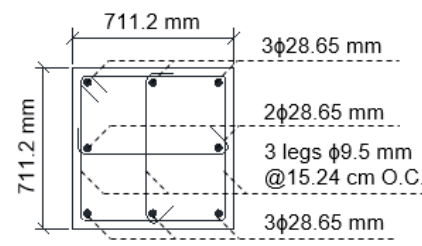

Center Sections (Section B-B)

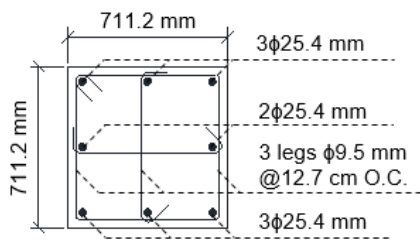

(c)

Figure 11: Column cross-section detailing: (a) SMRF columns at ground floor; (b) SMRF columns at upper floors; and (c) gravity columns.

\section{$324 \quad$ Finite element model}

The building is modelled in OpenSees (McKenna et al., 2010) as a two-dimensional model replicating one half of the full structure. Figure 12a illustrates the various components of the model that

327 include: one end moment resisting frame (with 8 columns), one interior moment resisting frame (with

3286 columns), six exterior columns that form part of the transverse exterior moment resisting frames (see

329 Figure 12b), and six internal gravity columns. All these components are linked by means of retainedconstrained node control so as to simulate the rigid diaphragm at each floor level.

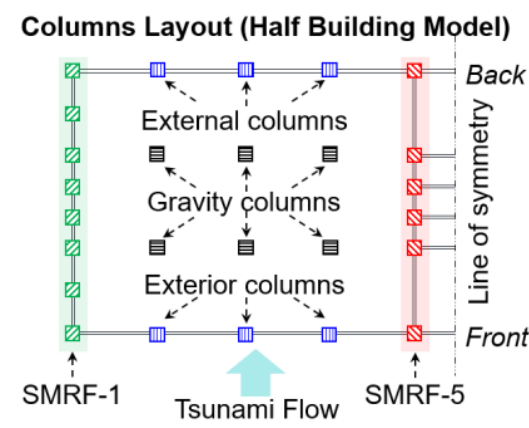

(a)

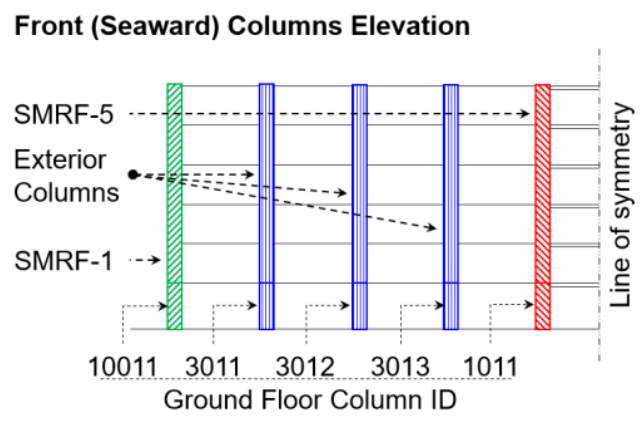

(b)

Figure 12: Main structural components for half of case-study building: (a) plan layout; and (b) elevation 
Beams and columns are modelled using force-based nonlinear beam-column elements. A

332 distributed plasticity model is adopted, since the inelastic behavior due to tsunami pressure can form at

333 any point along the column height. A fiber approach is used for the cross-sections with five integration

334 points along each element.

335 Expected material properties are calculated by multiplying nominal values by appropriate factors

336 in accordance with ASCE 41-17 (ASCE, 2017b). The expected concrete compressive strength is

337 increased by a factor of 1.25, i.e. $41.4 \mathrm{MPa}$, and 1.50 for reinforcing steel yield and tensile strengths,

338 i.e. $517 \mathrm{MPa}$ and $776 \mathrm{MPa}$, respectively. Reinforcing steel is assumed to have a strain hardening ratio

339 of 0.0057 and an ultimate steel strain of 0.22. The constitutive material Concrete04 in OpenSees, based

340 on Uniaxial Popovics material (Popovics, 1973) with an unloading and reloading stiffness model

341 according to Karsan and Jirsa (1969) and exponential decay for the strength, is employed to model

342 confined and unconfined concrete. It is noted that Concrete 44 model simulates stiffness degradation.

343 Concrete within the reinforcement cage is associated with a confined concrete constitutive law (Figure

344 13a), while the cover concrete outside the reinforcement cage is modelled as unconfined (Figure 13b).

345 Due to the low axial forces in the beams, concrete in the beams is modelled as unconfined. The steel

346 stress-strain constitutive material is modelled using the Giuffre-Menegotto-Pinto model (Filippou et al.,

347 1983), named Steel02 in OpenSees (Figure 13c).

348 Gravity loads are combined with the tsunami loads according to the load combination in Eqn. (3)

349 and are applied to the beams of the transverse frames and to the gravity columns.

350 Validation of the developed numerical model was conducted with respect to an independent model 351 of the same structure in Aegerter, (2021). The latter model is developed in ETABS using a lumped

352 plasticity approach. Comparison of ..... response showed a close agreement (within 5\%).

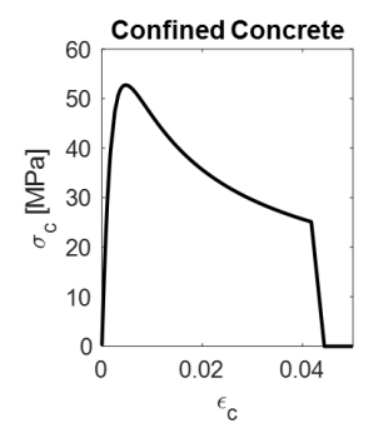

(a)

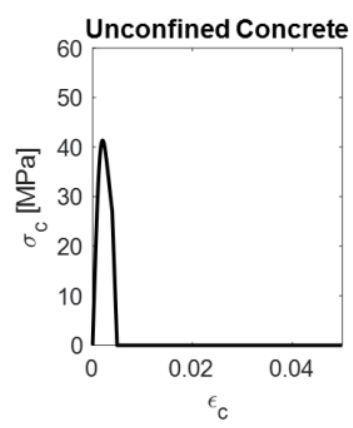

(b)

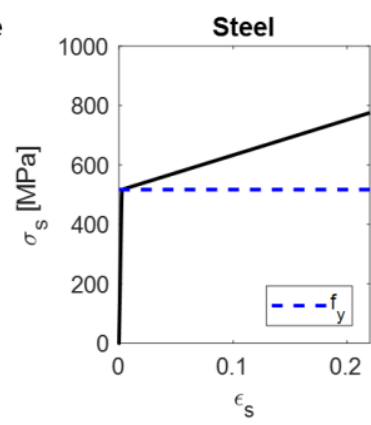

(c)

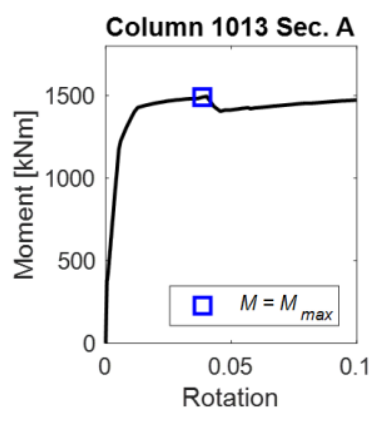

(d) 
Figure 13: (a) and (b) Concrete04 model for confined and unconfined concrete (Mander et al., 1988); (c) Steel02 model for steel (Filippou et al., 1983); and (d) moment-curvature at the end section of a ground floor column.

353

354

355

356

357

358

359

360

361

362

364

\section{Structural Performance Evaluation - Design Systemic Check}

The structural performance is evaluated at an applied tsunami force corresponding to LC2 for the design case. In this check, the maximum strength of the LFRS of the case study building, as calculated using the ASCE-VDPO2 approach, is compared to the LC2 loading. If the tsunami pushover curve shows the building to have a strength larger than the applied loading at LC2, then the systemic check is deemed to have been passed.

The performance of individual components of the structure should not be evaluated within the systemic analysis check, as the forces applied to these components are different from those imposed in the component-based check and will not provide the correct target component strengths for design or strengthening. However, as the former component loads are typically lower than in the componentbased check, observations of component failures can be indicative of problem areas within the structure. It is noted that, while $C_{\mathrm{D}}=2$ for component loading, $C_{\mathrm{D}}$ for the corresponding systemic force on the entire building varies from 1.25 to 2.0 and is typically lower than 2 (see Figure 2).

\section{Structural Performance Evaluation - Component-based Check}

In the component-based check, component failure is indicated when either its moment or shear capacity is reached. In particular, previous studies, (Petrone et al., 2017; Alam et al., 2018), have shown that a typical collapse mechanism for RC structures under tsunami loading is the occurrence of shear failure in the columns. This often precipitates global failure if no strengthening measures are adopted. Hence, in this study, shear failure occurrence is tracked in all ground-story columns (i.e. the seaward columns indicated in Figure 12b, which are subjected to the highest shear demand). It is assumed that local shear failure occurs when the shear force at any section of a column exceeds the nominal shear strength calculated according to the formulation of ASCE 41-17 (ASCE, 2017b):

$$
V_{\mathrm{n}}=k\left[\alpha \frac{A_{\mathrm{v}} f_{\mathrm{y}} d}{s}+\lambda\left(\frac{0.5 \sqrt{f_{\mathrm{c}}^{\prime}}}{M / V d} \sqrt{1+\frac{N}{0.5 \sqrt{f_{\mathrm{c}}^{\prime}} A_{\mathrm{g}}}}\right) 0.8 A_{\mathrm{g}}\right]
$$

where $A_{\mathrm{v}}$ is the area of shear reinforcement in a single set of hoops, $f_{\mathrm{y}}$ is the shear reinforcement yield strength, $d$ is the effective depth, $s$ is the hoop spacing, $k=1$ for low ductility demand, $\alpha=1$ for $s / d$ 
$<0.75, \lambda=1$ for normal-weight aggregate concrete, $f_{\mathrm{c}}^{\prime}$ is the compressive strength of concrete, $A_{\mathrm{g}}$ is the gross cross-sectional area, $N$ is the axial compressive force (set to zero for tension force), and $M / V d$ is the aspect ratio, which should not be taken as greater than 4 or less than 2 . In this study, it is assumed that $M / V=0.5 L_{\mathrm{col}}$, where $L_{\mathrm{col}}$ is the length of the column (e.g. $M / V d=3.23$ for ground floor SMRF columns). Since fluid forces on structural components are classified as force-controlled actions in ASCE $7-16$, the shear strength is calculated using the nominal material properties, in accordance with Figure C10-1 in ASCE 41-17 (ASCE, 2017b). Both the end and center column sections are checked due to differences in their shear reinforcement (Figure 11). The OpenSees model does not evaluate shear failure, so a separate shear check is performed on all columns post-analysis. In addition, to check whether columns experience shear failure before flexural yielding, a further check on the attainment of the maximum flexural moment, i.e. $M=M_{\max }$, is performed for the end sections, as illustrated in Figure 13d.

\section{RESULTS}

\section{Prescriptive systemic acceptance criteria}

ASCE 7-16 provides a simple criterion to evaluate the systemic tsunami capacity of a seismicallydesigned structure. This recognizes that a building designed to resist high seismic loading (i.e. Seismic Design Criteria D, E or F), has significantly greater inherent strength than the design seismic base shear, so portion of this overstrength can be utilized to resist the tsunami force (Chock et al., 2018). Effectively, the simplified check implies that the structural lateral force resisting system (LFRS) does not require additional lateral strength when:

$$
F_{\mathrm{T}, \mathrm{net}, \mathrm{LC} 2}<0.75 \Omega_{0} E_{\mathrm{h}}
$$

where $F_{\mathrm{T}, \text { net,LC2 }}$ is that portion of the maximum overall building tsunami load, $F_{\mathrm{T}, \mathrm{LC} 2}=32.603 \mathrm{kN}$ that is resisted by the LFRS, $\Omega_{0}$ is the system seismic overstrength factor and $E_{\mathrm{h}}$ is the base shear due to horizontal earthquake forces. As illustrated in Figure 7a, portion of this tsunami load $\left(f_{1}=10,894 \mathrm{kN}\right)$ is transferred directly to the foundations. The remaining $F_{\mathrm{T}, \mathrm{net}, \mathrm{LC} 2}=32,603-10,903=21,700 \mathrm{kN}$ must be resisted by the LFRS. For the prototypical building, $\Omega_{0}=3$ (for special MRFs, ASCE 7 Table 12.21) and $E_{\mathrm{h}}=10,831 \mathrm{kN}$, hence $\Omega_{0} E_{\mathrm{h}}=32,493 \mathrm{kN}$. The applied tsunami force $F_{\mathrm{T}, \mathrm{net}, \mathrm{LC} 2}=21,700 \mathrm{kN}$ is 
403 less than the limit of $0.75 \cdot 32,493=24,370 \mathrm{kN}$ from Eqn. (7). This check indicates that the seismic

404 lateral force resisting system should have sufficient strength to resist the overall tsunami loads.

\section{Systemic check via nonlinear static analysis - design}

406 Nonlinear static pushover analyses are employed to evaluate the lateral capacity of the structure to

407 resist tsunami loads. Figure 14a shows the total base shear-top drift curves from the seismic pushover 408 analysis along with the curve from the ASCE-VDPO2 with Phase 1 up to Load Case 2 and $S$ loading 409 discretization. This load pattern is selected as it is the one currently recommended in the commentary 410 of the ASCE 7-16 for evaluating the lateral force resisting system at LC2 (Robertson, 2020). The 411 tsunami pushover curve shows that the systemic tsunami capacity of the building is significantly larger 412 (by $40 \%)$ than the overall net tsunami load at LC2 $\left(F_{\mathrm{T}, \text { net,LC2}} / 2=21,700 / 2=10,850 \mathrm{kN}\right.$, shown as a 413 thick dashed line in Figure 14). Hence, the structure passes the systemic check of ASCE 7-16 when the 414 tsunami nonlinear pushover analysis is employed. It is noted that the systemic results have been 415 validated by a recent study (Aegerter, 2021), which developed a three-dimensional model of the same 416 building using the commercial software ETABS and employing a more standard lumped-plasticity 417 approach.

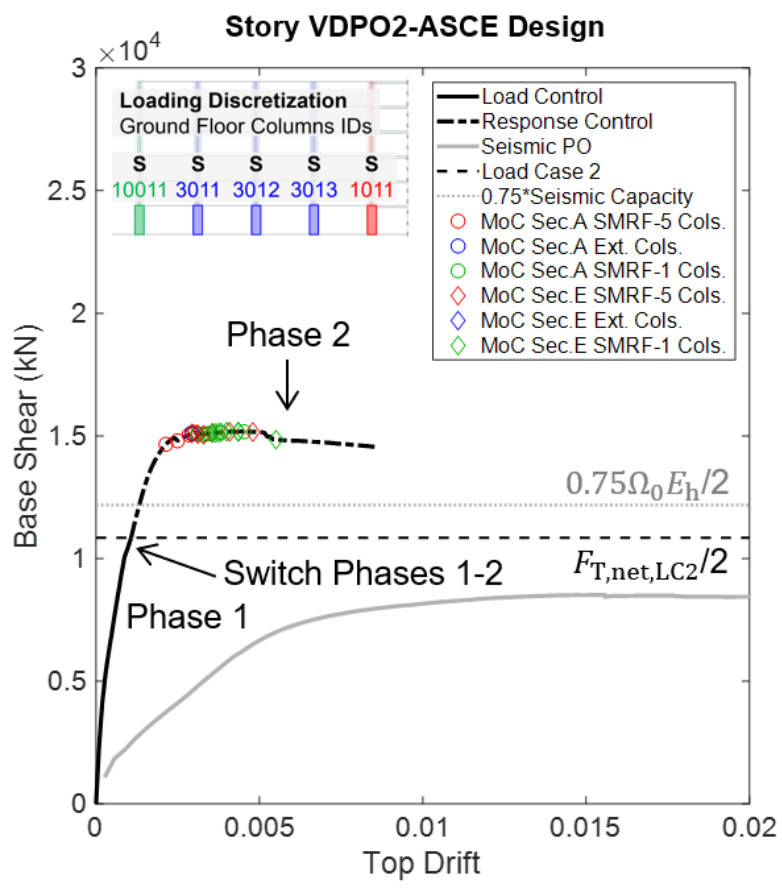

(a)

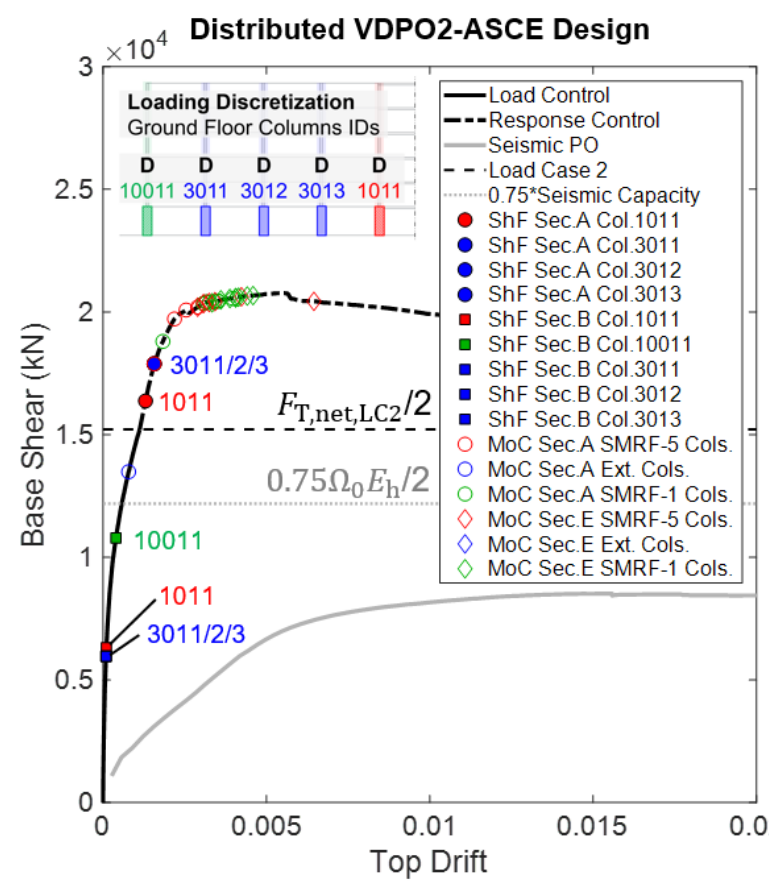

(b) 
Figure 14: Base shear-top drift curves of seismic pushover (PO) and ASCE-VDPO2 analyses (Design): (a) story loading discretization; and (b) distributed loading discretization. Filled and empty markers indicate the attainment of shear failure $(\mathrm{ShF})$ and maximum moment capacity $(\mathrm{MoC})$ in ground floor columns cross-sections (see Figure 11), respectively.

A seismic pushover analysis is also performed to draw a consistent comparison between the actual 419 lateral tsunami capacity with the corresponding seismic capacity. The seismic pushover is conducted using a lateral load distribution corresponding to the first mode response (fundamental period $=0.8 \mathrm{~s}$; first mode characterized by $83 \%$ mass participation factor). It is observed that under the tsunami lateral loading the case study building exhibits both a significantly increased stiffness and lateral load capacity than under seismic loading. The case study building shows a strength increase under tsunami loading of 1.8 times the seismic response. The difference in response is a natural consequence of the significantly different way in which seismic and tsunami loads act on a building. Tsunami loads are only applied at the lower floors of the building, while the seismic loads are applied at every story of the structure (where the mass is assumed to be concentrated) with increasing magnitude at higher stories. This seismic load distribution therefore results in much larger roof lateral deformations and additional associated P-Delta moments.

However, the relationship between the tsunami and seismic strength of a building is not simple to predict. Other studies that have evaluated both the seismic and tsunami base shear capacities of structures using seismic and various tsunami pushover methods (Rossetto et al., 2019; Petrone et al. 2020) show tsunami load capacities between 1.5 to 6 times larger than the respective seismic load capacities. These observations cast doubts as to the adequacy of the simplified systemic check within ASCE 7-16, which adopts the seismic design strength of a building as a predictor of its tsunami load resistance. Further questions are raised when the simplified check is conducted here using the actual seismic strength of the case study building instead of that estimated using the assumed overstrength factors. For the case study building, the actual seismic lateral capacity $(8,521 \cdot 2=17,042 \mathrm{kN})$ is larger than the design seismic base shear $\left(E_{\mathrm{h}}=10,831 \mathrm{kN}\right)$ as expected but is substantially less than that 440 predicted by the use of an overstrength factor $\Omega_{0}=3(32,493 \mathrm{kN})$. Hence, for this building it is apparent that the overstrength factor assumed in the ASCE 7-16 simplified check significantly overestimates the reserve lateral load capacity. The overstrength factor is used in seismic design to ensure that critical 
elements remain elastic while the yielding sections develop full plastic hinges. It is therefore biased to

444 being high in order to provide conservative seismic design. The 0.75 factor in Eqn. (7) is intended to

445

446 compensate for this bias, but it appears that this factor may be optimistic. It is important to note that if the simplified systemic check was conducted with the actual seismic base shear capacity of the structure (as predicted by the pushover), the structure would fail the check and a redesign of the LFRS would be required for it to resist the applied tsunami loads.

Due to the complexity in relating the seismic and tsunami strengths of structures it is not known if the simple systemic check allowed in ASCE 7-16 (Eqn. 7) is conservative or not. In most practical cases it is considered that the component checks will dominate the tsunami design/redesign of a structure. Nevertheless, it is recommended in this paper that non-linear structural tsunami analysis be used to conduct the systemic design check of ASCE 7-16 instead of the simplified check.

\section{The influence of load discretization assumptions on the systemic check}

As previously described, the $F_{\mathrm{T} \text {,net }}$ applied in the analyses with $S$ and $D$ loading discretization is different due to the portion of loading that is assumed transferred directly to the structure foundations. Also the center of load application is much higher in the structure for the S loading discretization. The difference in size and location of applied loads results in differences in the structural response under the two loading discretization assumptions.

In the $S$ loading discretization case, an apparent lower strength and stiffness of the structure is observed. It is seen that the higher level at which the loading is applied induces large moments, as well as shear forces, in the ground story columns of the structure. Bending failure of the columns (indicated by empty markers in Figure 14a) occurs without shear failure of columns. Instead, in the case of the $D$ loading discretization although the structure is subjected to a larger overall net tsunami force at LC2 $\left(F_{\mathrm{T}, \text { net,LC2 }} / 2=30,422 / 2=15,211 \mathrm{kN}\right.$, slightly smaller than $\left.F_{\mathrm{T}, \mathrm{LC} 2}\right)$, this load is only partially redistributed via the building diaphragms, resulting in larger shear forces than in the ground story columns and an overall increased stiffness and strength of the structure (see Figure 15b) as compared to the $S$ loading discretization case. From Figure $14 \mathrm{~b}$ it can be observed that the larger internal shear forces induce failure in the central portions (i.e. Section B) of the seaward columns, and not in the end 
sections where seismic design requirements for ductile response lead to increased transverse reinforcement (i.e. Section A). It is also noted that columns experience shear failure before flexural yielding, attained at the end cross-sections, i.e. $M=M_{\max }$ at Sections A and E illustrated in Figure 14b by empty markers.

Despite the significantly different structure responses, the evaluation of the systemic tsunami capacity of the building, using both $D$ and $S$ discretization, indicates that the structure satisfies the ASCE 7-16 requirement for collapse prevention without additional strengthening. It should be noted that this systemic check is not intended to be used in the evaluation of the individual component capacities (column shear or moment capacity) because this systemic loading does not replicate the component loading required by ASCE 7-16 Section 6.10.2.2. Component assessment for the prototype building is presented later in this paper and it will be seen that the ground floor columns fail the component-based check. However, as the component check applies distributed loads to the component assessed, and as $F_{\mathrm{T}, \text { net }}$ is larger in the $D$ load discretization case, applying the systemic load with the latter load discretization can provide an indication of which columns are likely to be critical when the component assessment is performed.

\section{Systemic check via nonlinear static analysis - assessment}

MCT, as shown in Figure 5b. Figure 15a shows the total base shear-top drift curves from the seismic pushover analysis and from the ASCE-VDPO2 with extended Phase 1 and $S$ loading discretization. While the analysis provides the same results up to LC2, it indicates that the building would have a maximum systemic tsunami capacity of $21,201 \cdot 2 \mathrm{kN}$. This force is slightly smaller than those obtained in the previous analyses (see Figure 15b), due to the larger bending actions that result from the increased inundation depths. The peak strength of the structure occurs when $h=7.25 \mathrm{~m}$ and $u=12.37 \mathrm{~m} / \mathrm{s}$, compared with $h=6.38 \mathrm{~m}$ and $u=11.56 \mathrm{~m} / \mathrm{s}$ for LC2. While this would correspond to an event with a return period longer than 2,500 years, it provides a measure of the building's reserve capacity for 
of the structure is $37 \%$ in this case, which provides a reasonable estimate of the extra systemic capacity of the structure.

\section{Component-based check via nonlinear static analysis}

ASCE 7-16 requires that all structural components be evaluated for hydrodynamic loads and that structural components.

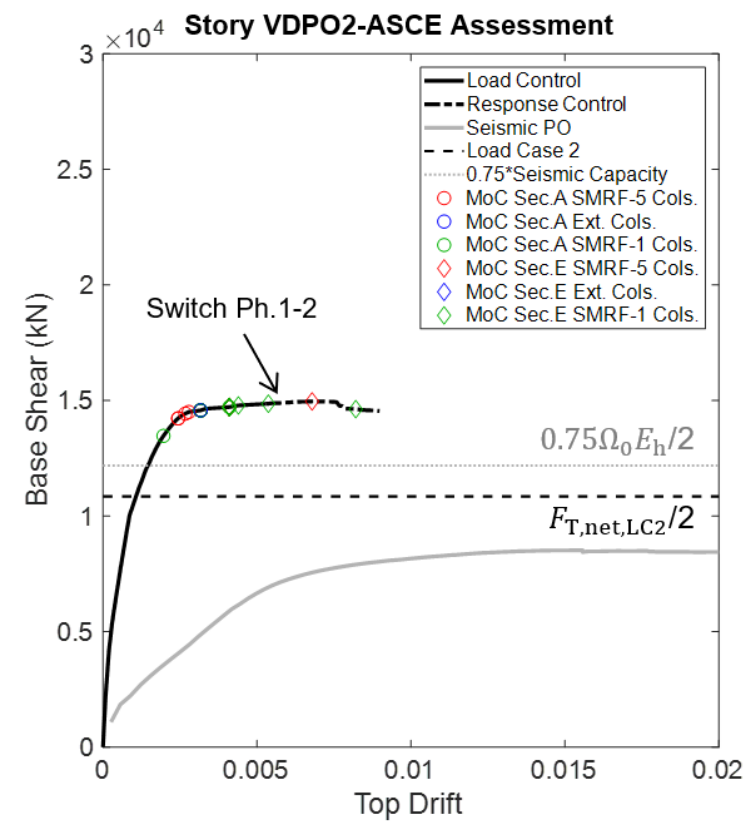

(a)

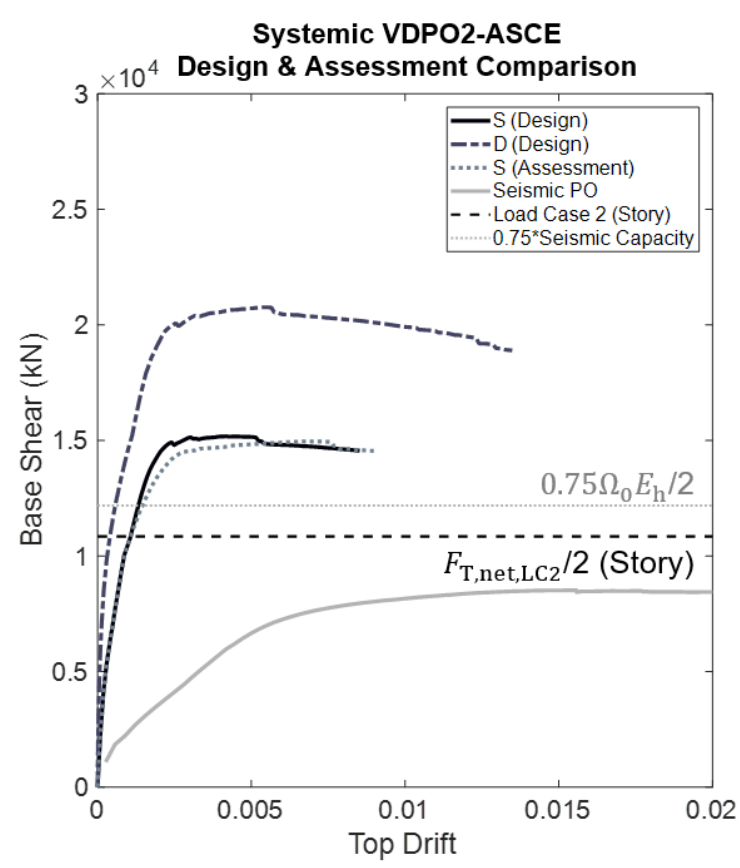

(b)

Figure 15: Base shear-top drift curves from seismic pushover (PO) and ASCE-VDPO2 analyses: (a) ASCE-VDPO2 with Phase 1 for Assessment and S loading discretization; and (b) comparison of systemic responses using Phase 1 for Design and Assessment and different loading discretization. Filled and empty markers indicate the attainment of shear failure

$(\mathrm{ShF})$ and maximum moment capacity $(\mathrm{MoC})$ in ground floor columns cross-sections (see Figure 11), respectively.

The structural component assessment is done individually for each seaward column using $C+S$ and $C+D$ loading discretization. Figure 16 presents the results of the pushover analyses with component loading on a typical external column and on the corner seaward column (i.e. part of SMRF-1). The worst load combination, presented in Figure 16a and b, occurs when the increased hydrodynamic loading is applied to any of the external columns (see Figures $6 \mathrm{c}$ and d). The results for the $C+S$ loading discretization (Figure 16a) show that the external column with the increased component loading (e.g. 
5113011 column) experiences shear failure in both center and end sections for tsunami forces much smaller

512 than the LC2 design load. In this case, the LC2 tsunami force for half of the building is larger than

$513 F_{\mathrm{T}, \text { net,LC2}} / 2$ calculated for the $S$ loading discretization, since it includes the increased drag force on the

514 component $F_{\mathrm{d}}$ and a share of the remainder $F_{\mathrm{T}, \text { net,LC2 }}-F_{\mathrm{d}}$. The latter is assigned to all remaining columns

515 on the front of the structure, including those not present in the current model of half of the building (see

516 Figure 6c). Figure 156c plots the results for the component check on the ground floor corner column

517 (i.e. 10011) that fails in flexure and in shear, but later in the pushover analysis than the exterior column

518 as a result of the smaller hydrodynamic load tributary area for the corner column.

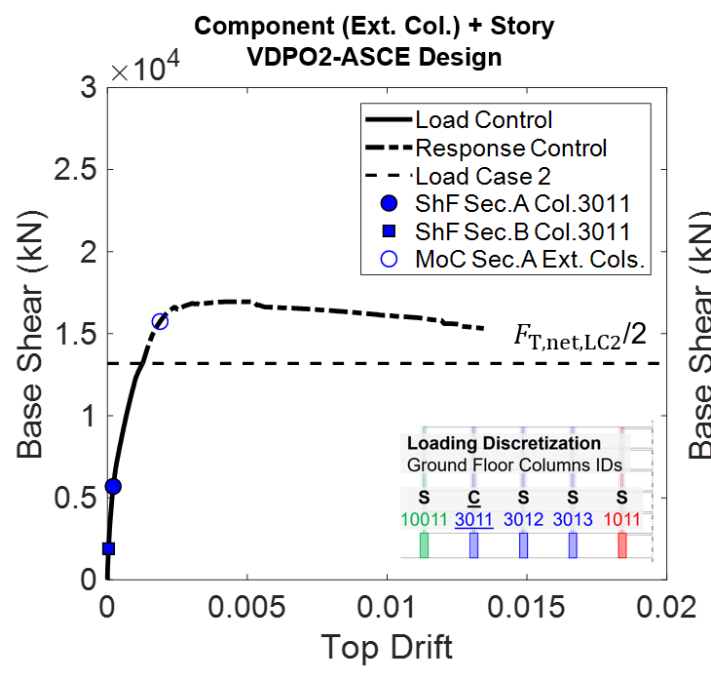

(a)

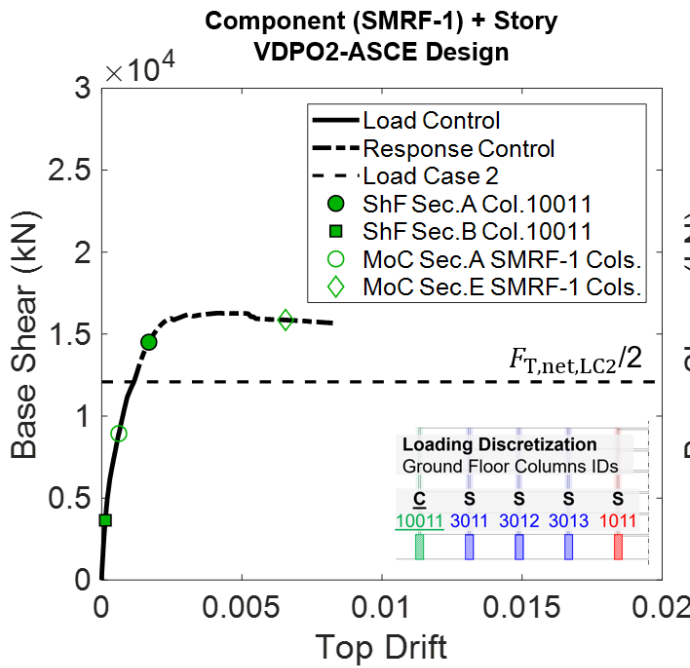

(c)

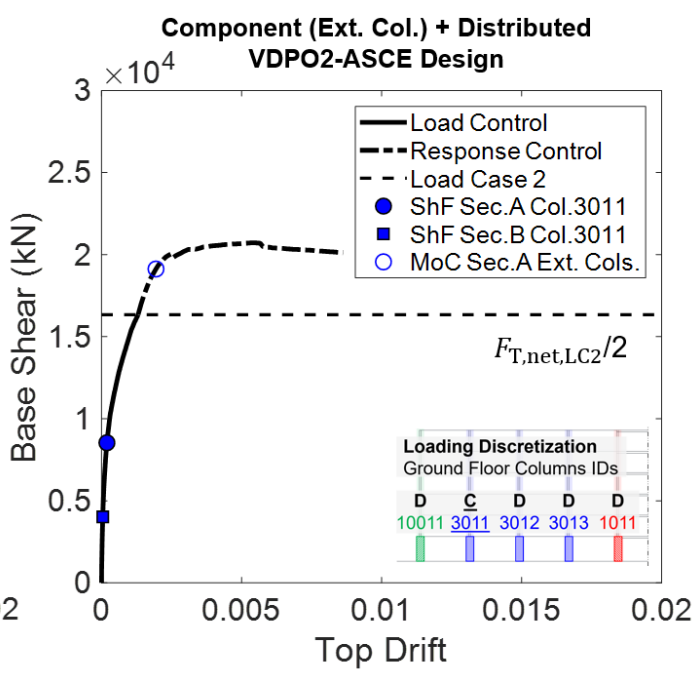

(b)

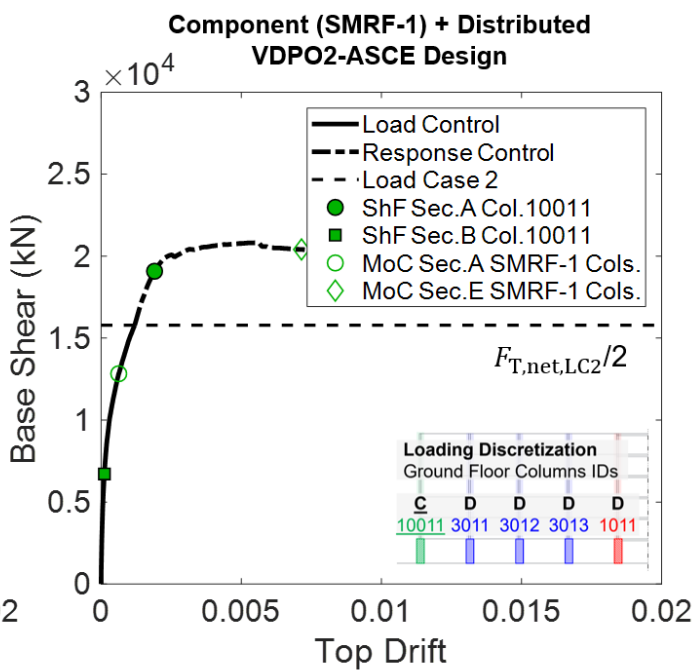

(d)

Figure 16: Base-shear-top drift curves for ASCE-VDPO2 analyses (Design): (a) $C+S$ loading discretization for one line of external columns; (b) $C+D$ loading discretization for one line of external columns; (c) $C+S$ loading discretization for the corner column; and (d) $C+D$ loading discretization for the line of corner column. Filled and empty markers indicate the attainment of shear failure $(\mathrm{ShF})$ and maximum moment capacity $(\mathrm{MoC})$ in ground floor column cross-sections (see

Figure 11), respectively. 
The pushover results for the $C+D$ loading discretization are shown in Figures $16 \mathrm{~b}$ and $\mathrm{d}$ for the exterior column (3011) and the corner column (10011), respectively. The shear and flexural failure points for the individual columns are equivalent to those observed in the $C+S$ loading discretization (Figures 16a and c) indicating that either story $(S)$ or distributed $(D)$ loading discretization can be used to apply the remainder of the systemic load to the rest of the building while component distributed load is applied to the columns being assessed.

If shear failure of the ground column is assumed as the structural failure criterion, the resulting tsunami capacity of the building is approximately a third of the design tsunami load under the required component loading combination. Therefore, the structure does not meet the collapse prevention performance level required for taller risk category II buildings without additional strengthening of all exterior and corner columns.

The use of a nonlinear static pushover analysis provides information on which components need to be strengthened and by how much, in order to improve the tsunami performance of the structure. For the case study building, this could be achieved by increasing the flexural and shear capacity of the ground floor seaward and landward exterior columns. For instance, no shear failure would occur if shear reinforcement is designed using \#4 ties with 5-cm-spacing for all seaward column sections (Figure 12).

\section{CONCLUSIONS}

This study presents a methodology for using nonlinear static pushover analysis within the framework of ASCE 7-16, called ASCE-VDPO2, and conducting the required systemic and componentbased design checks. An RC frame located in a high tsunami hazard area was considered as a casestudy. The ASCE-VDPO2 results were compared to the simplified ASCE 7-16 systemic tsunami capacity acceptance criterion, which compares the overall tsunami force to the design seismic base shear. The tsunami systemic capacity of the structure was seen to be sufficient to resist the ASCE 7-16 prescribed tsunami loads. However, the results highlighted that the relationship between the tsunami and seismic strength of a building is not simple to predict. Hence, it is recommended in this paper that non-linear structural tsunami analysis be used to conduct the systemic design check of ASCE 7-16 instead of the simplified check. The proposed procedure can also be used to assess the lateral force 
546 resisting system for inundation depths and flow velocities larger than the ones for design basis event,

547 providing an estimate of the extra systemic capacity of the structure. When component loading was

548 considered, the seaward ground story columns were observed to fail in shear, precipitating structural

549 failure. Because ASCE 7-16 requires that the same hydrodynamic conditions be considered during both

550 incoming and outgoing tsunami flow, the seaward and landward ground story columns would need to

551 be strengthened in flexure and shear. This approach has the potential for providing a more economical

552 design as compared to the prescriptive ASCE 7-16 approach, which promotes an enhanced seismic

553 design of the structure to meet the systemic acceptance criteria of the standard. The methodology is also

554 expected to produce cost savings through its implementation. The authors are continuing this study to

555 investigate these savings.

556 It is noted that the tsunami response of the case-study structure is evaluated considering only the

557 effects of the tsunami-induced hydrodynamic loads. Other possible effects caused by tsunami, e.g.

558 buoyancy, debris impact, scour, as defined in the ASCE 7-16 Standard, are not considered in this study.

559 APPENDIX. BEST-FIT APPROXIMATION EQUATIONS FOR ASCE 7-16 TSUNAMI

560 LOADS

561 Table 1. List of best-fit approximation equations for the drag coefficient $C_{\mathrm{d}}$ in ASCE 7-16 Table 6.10-1.

\begin{tabular}{lll}
\hline \multicolumn{1}{c}{ Segment } & \multicolumn{1}{c}{$\boldsymbol{B} / \boldsymbol{h}$} & \multicolumn{1}{c}{ Best-fit Approximation Equations } \\
\hline 1 & $0-12$ & $C_{\mathrm{d}}=1.25$ \\
2 & $12-16$ & $C_{\mathrm{d}}=0.0125 * B / h+1.1$ \\
3 & $16-36$ & $C_{\mathrm{d}}=0.01 * B / h+1.14$ \\
4 & $36-60$ & $C_{\mathrm{d}}=0.010417 * B / h+1.125$ \\
5 & $60-100$ & $C_{\mathrm{d}}=0.00125 * B / h+1.675$ \\
6 & $100-120$ & $C_{\mathrm{d}}=0.01 * B / h+0.8$ \\
7 & $>120$ & $C_{\mathrm{d}}=2$ \\
\hline
\end{tabular}

562 Table 2. List of best-fit approximation equations for the normalized curves of tsunami inundation depths and flow velocity in 563 ASCE7-16 Figure 6.8-1.

\begin{tabular}{lll}
\hline \multicolumn{1}{c}{ Segment } & \multicolumn{1}{c}{$\boldsymbol{t} / \boldsymbol{T}_{\text {TSU }}$} & \multicolumn{1}{c}{ Best-fit Approximation Equations $\left(x=t / T_{\mathrm{TSU}}\right)$} \\
\hline $\mathrm{A}$ & $0-0.178$ & $h / h_{\max }=3.745 x$ \\
$\mathrm{~B}$ & $0.178-0.5$ & $h / h_{\max }=4.194 x^{3}-7.457 x^{2}+4.525 x+0.077$ \\
$\mathrm{C}$ & $0.5-0.822$ & $h / h_{\max }=-4.225 x^{3}-5.19 x^{2}-2.24 x+1.35$ \\
$\mathrm{D}$ & $0.822-1$ & $h / h_{\max }=-3.745 x+3.745$ \\
$\mathrm{E}$ & $0-0.033$ & $u / u_{\max }=15.667 x$ \\
$\mathrm{~F}$ & $0.033-0.178$ & $u / u_{\max }=75.24 x^{3}-45.3 x^{2}+9.98 x+0.235$ \\
$\mathrm{G}$ & $0.178-0.444$ & $u / u_{\max }=0.527 x^{2}-2.825 x+1.485$ \\
$\mathrm{H}$ & $0.444-0.556$ & $u / u_{\max }=-5.95 x+2.975$ \\
$\mathrm{~J}$ & $0.556-0.822$ & $u / u_{\max }=-0.527 x^{2}-1.77 x+0.813$
\end{tabular}




\begin{tabular}{lll}
$\mathrm{K}$ & $0.822-0.967$ & $u / u_{\max }=75.7 x^{3}-181.7 x^{2}+146.27 x-40.5$ \\
$\mathrm{~L}$ & $0.967-1$ & $u / u_{\max }=15.667 x-15.667$ \\
\hline
\end{tabular}

564

565

566

567

568

569

570

571

572

573

574

575

576

577

578

579

580

581

582

583

584

585

586

\section{DATA AVAILABILITY STATEMENT}

All data, models, and code that support the findings of this study are available from the corresponding author upon reasonable request.

\section{ACKNOWLEDGMENTS}

The research work presented in this paper was funded by the European Research Council, ERC grant agreement 336084 URBANWAVES, awarded to Professor Tiziana Rossetto. The authors are grateful to Mr. Jacob McKamey for his assistance in this research. The authors also acknowledge Willis Research Network for supporting the time of Dr Crescenzo Petrone and Dr Marco Baiguera.

\section{REFERENCES}

Aegerter (2021). "A Method for Conducting Push-over Tsunami Analysis in Accordance with ASCE 7-16". MSc Thesis, University of Hawaii at Manoa.

Alam, M. S., Barbosa, A. R., Scott, M. H., Cox, D. T., and van de Lindt, J. W. (2017). “Development of Physics-Based Tsunami Fragility Functions Considering Structural Member Failures.” ASCE J. Struct. Eng., 144(3): 04017221.

ASCE (2017a), Minimum Design Loads and Associated Criteria for Buildings and Other Structures. ASCE/SEI 7-16. Reston, VA, USA.

ASCE (2017b), Seismic Evaluation and Retrofit of Existing Buildings. ASCE/SEI 41-17, Reston, VA, USA.

Attary, N., Unnikrishnan, V. U., van de Lindt, J.W., Cox, D. T., and Barbosa, A. R. (2017). "Performance-Based Tsunami Engineering Methodology for Risk Assessment of Structures.", Eng. Struct., 141, 676-686.

Atwater, B. F., Stuivert, M., and Yamaguchi, D. K. (1991). "Radiocarbon Test of Earthquake Magnitude at the Cascadia Subduction Zone.” Nature, 353, pp. 156-158. 
Baiguera, M., Rossetto, T., Robertson, I., and Petrone, C. (2019). “A nonlinear static procedure for the tsunami design of a reinforced concrete building to the ASCE7 Standard." In: Rossetto, T, (ed.)

Proceedings of the SECED 2019 Conference. SECED: London, UK.

Chock, G. Y., Carden, L., Robertson, I. N., Wei, Y., Wilson, R., and Hooper, J. (2018). “Tsunami-

Resilient Building Design Considerations for Coastal Communities of Washington, Oregon, and

California.” ASCE J. Struct. Eng., 144(8):04018116.

Filippou, F. C., Popov, E. P., and Bertero, V. V. (1983). "Effects of Bond Deterioration on Hysteretic Behavior of Reinforced Concrete Joints." Report EERC 83-19, Earthquake Engineering Research Center, University of California, Berkeley.

IBC (2018). International Building Code. Brea, CA: International Code Council.

Karsan, I.D., and Jirsa, J.O. (1969). "Behavior of concrete under compressive loading." Journal of

Kriebel, D. L., Lynett, P. J., Cox, D. T., Petroff, C. M., Riggs, H. R., Robertson I. N., and Chock

G. Y. K. (2017). "Energy Method for Approximating Overland Tsunami Flows.” Journal of Waterway, Port, Coastal, and Ocean Engineering, 143(5).

Macabuag, J., Lloyd, T., and Rossetto, T. (2014). “Sensitivity Analyses of a Framed Structure under Several Tsunami Design-Guidance Loading Regimes.” In Second ECES Conference. Istanbul.

McKamey, J., and Robertson, I. N. (2019). “Cost Implications for Including Tsunami Design in Mid-Rise Buildings along the US Pacific Coast”, Research Report. UHM/CEE/19-01.

McKenna, F., Scott, M. H., and Fenves, G. L. (2010) "Nonlinear finite-element analysis software architecture using object composition.” Journal of Computing in Civil Engineering, 24(1):95-107. 
Popovics, S. (1973). "A numerical approach to the complete stress strain curve for concrete. Cement 616 and Concrete Research.” 3(5), 583-599.

617 Qi, Z. X., Eames, I., and Johnson, E. R. (2014). "Force Acting on a Square Cylinder Fixed in a 618 Free-Surface Channel Flow.” Journal of Fluid Mechanics, 756, pp. 716-727.

619 Robertson, I. N. (2020). "Tsunami Loads and Effects: Guide to the Tsunami Design Provisions of 620 ASCE 7-16.” ASCE, Reston, VA.

621 Rossetto, T., Petrone, C., Eames, I., De La Barra, C., Foster, A., and Macabuag, J. (2018). 622 "Advances in the Assessment of Buildings Subjected to Earthquakes and Tsunami." In: Pitilakis K. 623 (eds) Recent Advances in Earthquake Engineering in Europe. ECEE 2018. Thessaloniki, Greece.

624 Rossetto, T., De la Barra, C., Petrone, C., De la Llera, J. C., Vásquez, J., and Baiguera, M. (2019). 625 "Comparative assessment of nonlinear static and dynamic methods for analysing building response 626 under sequential earthquake and tsunami.” Earthquake Engng Struct Dyn. 2019; 48: 867- 887.

627 Yokoyama, J., and Robertson, I. N. (2014). "Evaluation of Reinforced Concrete Buildings When 628 Subjected to Tsunami Loads.” Research Report. UHM/CEE/14-01. 